IdeAs

Idées d'Amériques

$1 \mid 2011$

Intégrations dans les Amériques

\title{
Entre la unión y la desunión: alcances y limitaciones de la integración centroamericana
}

Entre union et désunion: succès et limites de l'intégration centraméricaine Between union and disunion: achievements and limitations to Central American integration

Josette Altmann Borbón

\section{OpenEdition}

Journals

Edición electrónica

URL: https://journals.openedition.org/ideas/85

DOI: $10.4000 /$ ideas.85

ISSN: 1950-5701

Editor

Institut des Amériques

Referencia electrónica

Josette Altmann Borbón, «Entre la unión y la desunión: alcances y limitaciones de la integración centroamericana », IdeAs [En línea], 1 | 2011, Publicado el 31 agosto 2011, consultado el 18 octubre 2022. URL: http://journals.openedition.org/ideas/85 ; DOI: https://doi.org/10.4000/ideas.85

Este documento fue generado automáticamente el 18 octubre 2022

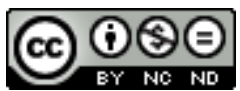

Creative Commons - Atribución-NoComercial-SinDerivadas 4.0 Internacional - CC BY-NC-ND 4.0 https://creativecommons.org/licenses/by-nc-nd/4.0/ 


\title{
Entre la unión y la desunión: alcances y limitaciones de la integración centroamericana
}

\author{
Entre union et désunion: succès et limites de l'intégration centraméricaine \\ Between union and disunion: achievements and limitations to Central American \\ integration
}

Josette Altmann Borbón

\section{Introduccion}

1 La región de América Latina atrae actualmente la atención de la comunidad internacional. En 2010, el Presidente del Banco Interamericano de Desarrollo (BID), Alberto Moreno, comenzó a hablar de la década latinoamericana (2010-2020). Si la región puede continuar el crecimiento económico, hacia 2025 habría doblado su ingreso por habitante y para ese entonces ya Brasil se habría convertido en la quinta economía mundial, sólo por debajo de China, Estados Unidos, India y Japón. La mayoría de estos países incluso podrían haber alcanzado el estatus de países desarrollados (The Economist 2010).

2 Sin embargo, la nueva bonanza económica se manifiesta de manera desigual en los distintos países de la región. El mejor desempeño se observa en los países exportadores de Sur América de materias primas (commodities), al contrario de lo que ocurre en los países importadores de productos básicos y dependientes del turismo y las remesas como son México, Centroamérica y el Caribe. Estos países están más integrados con Estados Unidos que nunca antes: demográficamente a través de las migraciones y económicamente a través de las remesas, el empleo en empresas estadounidenses y el intercambio comercial (Eguizaba 2010: 79). Incluso en la actual bonanza el crecimiento centroamericano es inferior al crecimiento sudamericano. En ese sentido, algunos analistas afirman que la década latinoamericana será más bien una década 
suramericana. Esta situación obliga a que se elaboren estudios desde y sobre la región centroamericana con el fin de analizar sus particularidades de forma tal que nuestros países también puedan sacar provecho de esta ventana de oportunidad.

3 La mayor parte de los estudios sobre Centroamérica se concentra en los temas de democracia y desarrollo, así como en la interrelación entre ambos. El primer estudio sobre el Estado de la Región -una de las iniciativas más importantes en la construcción de conocimiento desde y sobre el istmo- concluyó que al iniciar el siglo XXI, el principal desafío es la consolidación de Centroamérica como una región de paz, libertad, democracia y desarrollo. Es el desafío de constituir una comunidad pluralista de seguridad humana, basada en el crecimiento económico, equidad social, sostenibilidad ambiental y robustos lazos de integración y cooperación, en una región diversa y compleja (Proyecto Estado de la Región 1999: 52).

Desde el punto de vista del desarrollo, las discusiones siguen centradas en cuál debe ser el modelo de desarrollo que debe ponerse en práctica en la región. El modelo neoliberal y las políticas del Consenso de Washington fueron dominantes en las últimas décadas del siglo XX, privilegiando la apertura económica y la expansión comercial. Se concentró en la diversificación de las exportaciones y de los mercados, en la atracción de la inversión extranjera directa, en la reducción del ámbito del Estado, apertura o privatización de empresas públicas y una política macroeconómica centrada en obtener la estabilidad y controlar la inflación.

5 Las políticas económicas implementadas no fueron tan exitosas como se esperaba, acarreando consigo el cuestionamiento del modelo por sus efectos sociales negativos, lo que ha replanteado de nuevo los debates en torno al papel del Estado en la búsqueda del desarrollo. A diferencia de los años ochentas y noventas, la pregunta esencial no si debe haber más o menos Estado, sino en cómo articular las políticas sociales y económicas. Asimismo, las nuevas orientaciones se enfocan en generar una alianza estratégica efectiva entre el sector privado y el sector público.

6 La introducción de los temas ambientales es otro aspecto relevante, especialmente en el contexto del cambio climático, donde se vuelve a replantear recuperar lo planteado y desarrollado por la Alianza Centroamericana para el Desarrollo Sostenible (ALIDES) firmada en el año 1994 por todos los presidentes centroamericanos. La ALIDES contempló compromisos regionales en 2 áreas fundamentales: 1 . Legislación ambiental y recursos naturales; y 2. Legislación reglamentando evaluaciones de impacto ambiental, agua, energía, control de contaminación y desarrollo fronterizo. En su momento fue una iniciativa de importante proyección internacional por plantear un desarrollo novedoso y sustentable.

7 Otros desafíos mencionados para la región son la necesidad de ofrecer trabajo a sus habitantes, contar con personas saludables, garantizar alimentos a sus habitantes, contar con energía para impulsar su desarrollo, no expulsar a la población y alcanzar la inserción ventajosa en la economía internacional. El gran desafío sigue siendo combatir la desigualdad. Los beneficios que pueda derivar la población del crecimiento económico dependen de los avances que puedan lograr los países en la disminución de la fuerte inequidad.

8 El otro gran tema de debate ha sido la integración regional y los alcances y limitaciones que ha tenido este proceso en Centroamérica. En 1960 se constituyó el Mercado Común Centroamericano en el marco del modelo de sustitución de importaciones. La guerra entre El Salvador y Honduras truncó el proyecto. Las guerras civiles de los años 80 
frustraron toda opción integracionista. A partir de la década de los noventa, se reformó y relanzó el proceso y con el Protocolo de Tegucigalpa se constituyó el Sistema de Integración Centroamericana (SICA) en el marco del regionalismo abierto. Asimismo, se inició un proceso de apertura comercial hacia terceros países.

Existe un acuerdo amplio en los círculos académicos y gubernamentales de que la integración económica de América Central se ha fortalecido notablemente en los últimos 15 años. Este consenso está respaldado por el crecimiento significativo del comercio intra-regional. Este proceso ha ocurrido de manera no real y no formal, fuera del marco de los instrumentos de integración regionales (Segovia 2005: 12). Es decir, que el proceso ha sido liderado por los grupos de poder económico regionales y las empresas transnacionales y no por los Estados y las instituciones.

10 En este proceso de apertura comercial, otro tema que capturó la atención tanto de académicos como políticos fue la firma del tratado de libre comercio (TLC) con Estados Unidos (CAFTA-DR). Quienes lo apoyan aseguran que por medio del tratado se garantizará un acceso preferencial a un mercado de 300 millones de personas, con lo que al incrementarse las oportunidades de exportar, se incide en creación de fuentes de trabajo y en la reducción de la pobreza. A los opositores al TLC les preocupa que las diferencias en los niveles de desarrollo entre Estados Unidos y los países centroamericanos incrementen la pobreza y las desigualdades (Nowalski Osterlof, 2010:82). Los debates trascendieron al tratado mismo y abrieron en todos los países una discusión sobre los impactos de la apertura económica y de la expansión comercial en la región. Contribuyó para que se abriera la discusión respecto del rumbo por el cual deben transitar los países para lograr su desarrollo de forma sostenible (Ibíd., pp. 114-115). La polémica se profundizó con la crisis económica y la recesión de los países desarrollados.

11 Al analizar el proceso de integración centroamericana, muchos autores ${ }^{1}$ resaltan las fuertes asimetrías entre los países del istmo. Por un lado, existen divergencias en la forma de concebir el proceso de integración regional. En un extremo están quienes pregonan el minimalismo inter-gubernamentalista, la idea de limitar la integración al establecimiento de relaciones de cooperación entre países a propósito de ciertos intereses comunes. En el otro extremo están quienes propugnan el maximalismo comunitario, el establecimiento de un bloque regional con robustas instituciones supranacionales (Programa Estado de la Nación, 2008: 76).

12 Por otro lado, el Proyecto del Estado de la Región indica que en Centroamérica es posible distinguir dos estilos de inserción en la economía internacional. Primero, una inserción internacional de bajo nivel tecnológico basada en la agro exportación y la industria de maquila textil; altos volúmenes de emigración y flujo de remesas; poca capacidad de atracción de inversión extranjera; nivel exportador bajo o intermedio con fuerte peso del mercado centroamericano; y magros resultados económicos y sociales. Una segunda que combina la inserción internacional basada en mayor incorporación tecnológica; bajos o nulos volúmenes de emigración y flujos de remesas; mayor capacidad de atracción de inversión; alto nivel exportador orientado a mercados extra regionales y resultados económicos y sociales intermedios (Ibid.: 58).

13 Pasando al segundo tema de interés, la democracia, la región ha entrado en un nuevo momento del proceso de democratización. A diferencia del período anterior en los noventa, en el cual los avances fueron muchos y rápidos en la eliminación de los autoritarismos, la época actual se caracteriza por avances democráticos más 
esporádicos y lentos(Proyecto Estado de la Región-PNUD, 2003:37). Se ha criticado en múltiples ocasiones que las democracias de América Latina son de baja intensidad. La democracia electoral está consolidada, no así la democracia social y económica, y por ende, tampoco la legitimidad de los Estados. Hace falta que gobernantes electos democráticamente gobiernen democráticamente (Ibid.: 23).

Entre los desafíos más resaltados están las debilidades de financiamiento partidario y la desigualdad entre partidos con respecto al acceso de estos a la ciudadanía. Entre otros desafíos están la estabilidad democrática, la lucha contra la corrupción y la búsqueda de la transparencia y la consolidación de los Estados de Derecho. Otro tema que ha venido adquiriendo particular relevancia es el fortalecimiento de los gobiernos locales.

Existe un desequilibrio entre el discurso político a favor de la descentralización, la estructura institucional y la gestión pública realmente existente. La democratización de los regímenes políticos municipales no ha tenido avances sustantivos durante la primera década del siglo XXI. Su debilidad financiera y administrativa es la principal barrera para su consolidación, pues dependen de las transferencias de los gobiernos centrales (Programa Estado de la Nación, op.cit.:69-70).

Las municipalidades poseen un conocimiento profundo de las realidades locales y están estrechamente involucradas en las actividades productivas como proveedoras de bienes y servicios públicos, infraestructura, recaudadoras de impuestos y el ordenamiento, control y planificación del territorio. Además, les corresponde mantener el vínculo entre el gobierno central, la sociedad civil, el sector productivo y el municipio, siendo el canal por excelencia para potenciar la canalización eficiente de los recursos públicos y privados hacia una visión común de desarrollo (FUNDEMUCA, 2011:4).

Un tema que adquiere cada vez mayor importancia es el de la erosión de los Estados de Derecho por el crimen organizado y la inseguridad ciudadana (Solis, 2008). Varios estudios se han abocado a analizar este tema a profundidad (La Red Centroamericana de Centros de Pensamiento e Incidencia, 2011: 12). Centroamérica -y en especial los países que forman su "Triángulo Norte" (Guatemala, Honduras y El Salvador) - es la región más violenta del mundo. Si se exceptúan las guerras que padecen algunas partes de África o de Asia, esta región registra las tasas de homicidio más elevadas del planeta. La inseguridad ciudadana es identificada por la población en la mayoría de países del istmo como el problema principal.

Mientras el crimen organizado para Estados Unidos y Europa es un problema de seguridad, para América Latina ya constituye además un problema de gobernabilidad. En particular el narcotráfico ha creado estructuras paralelas al Estado, sustituyendo lo que el Estado, la economía y los mercados tradicionales no pueden dar (La Red Centroamericana de Centros de Pensamiento e Incidencia, 2011:12).

Los principales problemas en torno a la seguridad son los siguientes (Ibid.:19): Primero, que Centroamérica se encuentra inmersa en su conjunto en una geopolítica de narcotráfico. La región se encuentra ubicada entre la principal zona productora y la principal zona consumidora de drogas de América. Segundo, están las actividades de las pandillas juveniles y las maras; las cuales se vinculan a la extorsión, secuestros y menudeo, y que en años recientes han procurado controlar espacios o territorios. Además, hay fuertes indicios de su vinculación instrumental al crimen organizado (Solis, 20098: 79-109). Tercero, en la mayoría de los países de la región los Estados de 
Derecho son débiles e incipientes (Rojas Aravena, 2010). Y un cuarto factor de inseguridad es el fácil acceso a las armas ligeras (Sáenz Breckenridge, 2007).

En el marco de estos enfoques académicos, este trabajo se concentra en el tema de la integración regional como factor clave en la búsqueda del desarrollo. Los países pequeños son tomadores de oportunidades, no generadores de políticas globales, por lo que la integración se convierte en un instrumento fundamental para "tener voz" en los foros internacionales. La hipótesis es que en la integración reposa la ventaja comparativa de Centroamérica en un mundo globalizado y cada vez más competitivo. Es el camino para enfrentar los desafíos que, luego del cese del enfrentamiento armado hace ya más de dos décadas, requieren hacer de la región un lugar más equitativo, más inclusivo y más desarrollado. Será además un factor en que la década 2010-2020 no sólo sea suramericana, sino verdaderamente latinoamericana.

La integración pasa por el reconocimiento de la diversidad, la pluralidad étnica, ecológica y política que caracteriza la historia regional. La diversidad lejos de debilitar, fortalece cuando se basa en la adhesión a un proyecto común, a una agenda cimentada en temas que estén por encima de las diferencias ideológicas de cada gobierno para hacer frente a los retos de la gobernabilidad, la lucha contra la pobreza, el uso racional de los recursos naturales, el desarrollo de economías sanas, competitivas y eficientes y los efectivos elementos de la cohesión social.

Todos estos son esfuerzos de largo plazo cuya ejecución pasa por mecanismos institucionales que, en democracia, se vuelven más intrincados bajo las reglas y pesos y contrapesos propios de los sistemas republicanos. La agenda centroamericana hoy no radica en la realización de acciones puntuales que se agotan en sí mismas y generan titulares como fueron el cese al fuego, el acuerdo para realizar elecciones, el proyecto de retorno de desplazados, la reapertura de un periódico, y la firma de un Plan de Paz, sino en el gradual y silencioso sostenimiento de los procesos sociales que, además de su complejidad, deben soportar la indiferencia de los poderosos Estados que participaron y en ocasiones estimularon- el conflicto centroamericano.

El artículo se divide en cuatro apartados. Primero, se muestran los principales indicadores sociales y económicos de la subregión 25 años después de los procesos de paz. Segundo, el artículo aboca la búsqueda de procesos de integración con mayor sentido político. En este marco, seguidamente, se señalan los principales desafíos del Sistema de Integración Centroamericana, así como la necesidad de incluir aspectos sociales de forma paralela al proceso de integración económica-comercial. Posteriormente, y desde una perspectiva más macro, se resume el estado de las relaciones de Centroamérica con el resto del mundo (el impacto del ALBA, el impacto del CAFTA-DR y las relaciones con la UE y Asia-Pacífico). Finalmente, en las conclusiones se señalan los principales desafíos a vencer en la sub-región.

\section{A 25 años de esquipulas}

24 A poco más de veinte años de los procesos de Esquipulas, Centroamérica cambió. En estos años la región ha transitado -para bien- de la guerra a la paz, sin haber logrado enlazar con igual éxito las iniciativas de integración regional y de desarrollo social. En estas dos décadas el proceso ha sido de claroscuros; ha producido resultados positivos, pero también se manifiestan importantes debilidades. Lejos de haber mejorado, la situación de pobreza y exclusión siguen siendo tremendas en la región. A pesar de que 
la reducción de la pobreza durante los años noventa y parte de la actual década está relacionada con el cese de la inestabilidad política, lo cierto es que en términos porcentuales se reduce la pobreza, pero en cifras absolutas el número de pobres.

Los países centroamericanos deben enfrentar numerosos desafíos en lo político, lo económico, lo social y lo cultural. El escenario regional se encuentra agitado. Nicaragua y Costa Rica están enfrentadas en los tribunales internacionales y foros regionales (Corte de Justicia de La Haya y la Organización de Estados Americanos, por mencionar los principales) a causa de la invasión de Nicaragua a suelo costarricense en Isla Calero. La institucionalidad de la región es débil y ha recibido severos golpes en los últimos dos años. Nicaragua ha sido censurada internacionalmente por las interrogantes del fraude electoral en las elecciones municipales (2008), la forma poco transparente en que algunos magistrados leales al gobierno permanecieron en sus puestos con el fin de asegurar la modificación constitucional para la reelección del Presidente Ortega, y las conexiones de ese país con Libia e Irán. Políticamente Honduras vive todavía los efectos del golpe de Estado (2009), a pesar del reciente acuerdo entre el presidente Lobo y el Expresidente Zelaya que han permitido que es país se reincorpore de nuevo a la OEA (2011), foro del que fue expulsado luego del golpe. Honduras todavía tiene pendientes las denuncias surgidas de organismos internacionales por violaciones de Derechos Humanos. En el caso de Guatemala, el reciente divorcio presidencial para que la Primera Dama pudiera ser considerada candidata presidencial en las próximas elecciones presidenciales de ese país a celebrase el 11 de septiembre de 2011, ha generado importantes debates en relación a la debilidad de las instituciones. De igual manera, este país sufre los efectos negativos de la delincuencia y el crimen organizado, entre otros, por las guerras fallidas contra los carteles de la droga en México. Aunado a la anterior, las estadísticas regionales en materia de pobreza y desarrollo humano son poco alentadoras para los países del CA4 (Guatemala, El Salvador, Honduras y Nicaragua) en comparación con las cifras de Panamá y de Costa Rica.

La incidencia de la pobreza es alta en la mayoría de los países donde, con la excepción de Costa Rica y Panamá, en Guatemala, Honduras y Nicaragua se aproxima o supera los dos tercios de la población, superando el promedio de pobreza de América Latina para el 2009 (33,1\%) (CEPAL, 2010: 65). Asimismo, salvo en el caso de Costa Rica, las brechas entre pobreza rural y pobreza urbana son evidentes en el resto de los países.

Cuadro 1 Centroamérica: pobreza y pobreza extrema según región (En términos porcentuales según área geográfica)

\begin{tabular}{|l|l|l|l|l|l|l|}
\hline & $\begin{array}{l}\text { Costa Rica } \\
(2009) \mathrm{a})\end{array}$ & $\begin{array}{l}\text { El Salvador } \\
(2009) \mathrm{a})\end{array}$ & $\begin{array}{l}\text { Guatemala } \\
(2006) \mathrm{a})\end{array}$ & $\begin{array}{l}\text { Honduras } \\
(2007) \mathrm{a})\end{array}$ & $\begin{array}{l}\text { Nicaragua } \\
(2005) \mathrm{a})\end{array}$ & $\begin{array}{l}\text { Panamá } \\
(2009) \mathrm{a})\end{array}$ \\
\hline Pobreza Total & 18,9 & 47,9 & 54,8 & 68,9 & 61,9 & 26,4 \\
\hline Urbana & 18,5 & 42,3 & 42,0 & 56,9 & 54,4 & 16,3 \\
\hline Rural & 19,5 & 57,6 & 66,5 & 78,8 & 71,5 & 43,9 \\
\hline $\begin{array}{l}\text { Pobreza Extrema } \\
\text { Total }\end{array}$ & 6,9 & 17,3 & 29,1 & 45,6 & 31,9 & 11,1 \\
\hline
\end{tabular}




\begin{tabular}{|l|l|l|l|l|l|l|}
\hline Urbana & 5,4 & 12,8 & 14,8 & 26,2 & 20,8 & 4,6 \\
\hline Rural & 9,1 & 25,2 & 42,2 & 61,7 & 46,1 & 22,3 \\
\hline
\end{tabular}

a) Año más reciente del que se dispone información.

Fuente: CEPAL, Anuario Estadístico de América Latina y el Caribe 2010, Santiago de Chile: CEPAL, 2010, p. 65. < http://www.eclac.org/publicaciones/xml/6/42166/LCG2483b_contenido.pdf > Accesado el 10 de mayo de 2011.

Sin embargo, más que la pobreza, la cual ha disminuido en los últimos años de crecimiento económico, el mayor problema es la desigualdad. América Latina es la región más desigual del mundo. Existen altas asimetrías entre los países centroamericanos, así como a lo interno de ellos. La población más pobre de la región sólo obtiene, en promedio, un 3.25\% del total de la riqueza, mientras que el quintil más rico concentra el $57.68 \%$.

Cuadro 2 Centroamérica: Distribución del ingreso en el Quintil más pobre y el Quintil más rico (En términos porcentuales)

\begin{tabular}{|l|l|l|l|l|l|l|}
\hline & $\begin{array}{l}\text { Costa Rica } \\
(2009)\end{array}$ & $\begin{array}{l}\text { El Salvador } \\
(2009)\end{array}$ & $\begin{array}{l}\text { Guatemala } \\
(2006)\end{array}$ & $\begin{array}{l}\text { Honduras } \\
(2007)\end{array}$ & $\begin{array}{l}\text { Nicaragua } \\
(2005)\end{array}$ & $\begin{array}{l}\text { Panamá } \\
(2009)\end{array}$ \\
\hline Quintil 1 & 3,8 & 4,3 & 2,8 & 1,9 & 3,5 & 3,2 \\
\hline Quintil 5 & 55,2 & 53,0 & 62,9 & 60,9 & 57,7 & 56,4 \\
\hline
\end{tabular}

Fuente: CEPAL, Anuario Estadístico de América Latina y el Caribe 2010, op. cit., p. 67. Accesado el 10 de mayo de 2011.

Asimismo, la democracia en Centroamérica es todavía demasiado formal y las estructuras de poder no han sido modificadas sustantivamente, pese a que en los Acuerdos de Paz de Esquipulas II, firmados en la Segunda Cumbre de Presidentes Centroamericanos el 7 de Agosto de 1987 en Guatemala, se conceptualizó el proceso de democratización como el establecimiento o perfeccionamiento de "sistemas democráticos, representativos y pluralistas que garanticen la organización de partidos políticos y la efectiva participación popular en la toma de decisiones"2. Aún ahora, los organismos públicos de control del Estado siguen siendo bastante débiles a nivel institucional, lo que se traduce en falta de capacidad técnica, limitados recursos financieros, duplicidad de roles en la función pública y vacíos legales para señalar responsabilidades.

En la sección 9 de Esquipulas II sobre cooperación, democracia y libertad para la paz y el desarrollo, se estableció un fuerte vínculo entre democracia, desarrollo, crecimiento económico y cohesión social. Esto, si bien permitió avanzar en las áreas de estabilidad económica, apertura comercial y una fuerte reactivación de la integración económica regional, no logró impulsar una economía de bienestar que permitiera un clima de libertad para garantizar que los países de Centroamérica pudieran adoptar una serie de acuerdos que propiciaran el desarrollo para alcanzar sociedades más justas, igualitarias y libres de miseria. ${ }^{3}$ 
30 A partir de la década de los noventa se inicia en la región una fase de integración económica que tiene como principales actores a las empresas transnacionales y a grupos regionales de poder económico, denominado integración real. ${ }^{4} \mathrm{Si}$ bien el proceso ha generado un aumento de las exportaciones y un incremento en la inversión extranjera directa (IED), también ha creado una mayor concentración de la riqueza y no ha logrado promover un crecimiento sostenible de las economías.

Cuadro 3 Centroamérica: Flujos de Inversión Extranjera Directa (En millones de dólares)

\begin{tabular}{|l|l|l|l|l|l|l|l|l|l|}
\hline & 2001 & 2002 & 2003 & 2004 & 2005 & 2006 & 2007 & 2008 & 2009 \\
\hline Costa Rica & 460 & 659 & 575 & 794 & 861 & 1469 & 1896 & 2021 & 1323 \\
\hline El Salvador & 279 & 470 & 142 & 363 & 511 & 241 & 1509 & 784 & 431 \\
\hline Guatemala & 499 & 205 & 263 & 296 & 508 & 592 & 745 & 754 & 566 \\
\hline Honduras & 304 & 275 & 403 & 547 & 600 & 669 & 928 & 900 & 500 \\
\hline Nicaragua & 150 & 204 & 201 & 250 & 241 & 287 & 382 & 626 & 434 \\
\hline Panamá & 405 & 78 & 771 & 1004 & 962 & 2498 & 1777 & 2402 & 1773 \\
\hline
\end{tabular}

Fuente: UNCTAD, "Foreign Direct Investment Flows 1970-2009". < http://unctadstat.unctad.org/ TableViewer/tableView.aspx?Reportld=88> Accesado el 10 de mayo de 2011.

31 Por otro lado, las remesas se han convertido en una fuente importante de divisas para algunos de los países centroamericanos, donde en los casos de El Salvador y Honduras el importe de éstas prácticamente dobla el valor de las exportaciones de mercaderías, convirtiéndolas en la principal fuente de divisas para esos dos países.

Cuadro 4 América Central: Remesas Recibidas (En Millones de dólares)

\begin{tabular}{|l|l|l|l|l|l|l|l|l|l|l|}
\hline & 2001 & 2002 & 2003 & 2004 & 2005 & 2006 & 2007 & 2008 & 2009 & 2010 \\
\hline Costa Rica & 198 & 251 & 321 & 320 & 420 & 513 & 618 & 605 & 513 & 622 \\
\hline El Salvador & 1926 & 1954 & 2122 & 2564 & 3030 & 3485 & 3712 & 3804 & 3482 & 3648 \\
\hline Guatemala & 634 & 1600 & 2147 & 2628 & 3067 & 3700 & 4236 & 4460 & 4026 & 4255 \\
\hline Honduras & 623 & 818 & 883 & 1175 & 1821 & 2391 & 2648 & 2869 & 2520 & 2662 \\
\hline Nicaragua & 336 & 377 & 439 & 519 & 616 & 698 & 740 & 818 & 768 & 803 \\
\hline Panamá & 73 & 85 & 107 & 109 & 130 & 157 & 180 & 196 & 175 & 198 \\
\hline
\end{tabular}

Fuente: UNCTAD, "External financial resources. Migrants remittances 1980-2010". < http:// unctadstat.unctad.org/TableViewer/tableView.aspx > Accesado el 10 de mayo de 2011. 
El proceso de apertura comercial en la región ha promovido una reestructuración de la oferta exportable, pero ha venido acompañado de un incremento de las importaciones. Según datos de la Secretaría de Integración Económica Centroamericana (SIECA), en el 2009 -sólo Centroamérica sin Panamá- las exportaciones fueron alrededor de US \$19 mil millones, mientras que las importaciones fueron aproximadamente US \$37 mil millones. Estas cifras señalan para la región un déficit comercial de aproximadamente US \$18 mil millones (SIECA, 2009).

Y si se compara el monto total recibido por las remesas con la inversión extranjera directa, se podría suponer que el déficit comercial de algunos países se está financiando con la "exportación" de seres humanos. La diferencia entre las remesas y la inversión extranjera directa es aún mayor si no se considera a Costa Rica, pues este país absorbe gran parte de la inversión extranjera directa dirigida hacia la subregión. El total de IED sin considerar Costa Rica disminuiría a \$1,931 millones de dólares.

Cuadro 5 Centroamérica: Remesas e Inversión Extranjera Directa (2009) a) (En Millones de dólares)

\begin{tabular}{|l|l|}
\hline Remesas & US\$11.401 \\
\hline IED & US\$3.254 \\
\hline
\end{tabular}

a) Cálculo con base en datos de 2009 pues no hay datos de IED para 2010.

Fuente: UNCTAD, "Foreign Direct Investment Flows 1970-2009", op. cit. y UNCTAD, "External financial resources. Migrants Remittances 1980-2010", op. cit.

Todo ello permite inferir que aún no existen condiciones para hablar de una Centroamérica refundada sobre las bases de la solidaridad y la justicia que tanto anhelan sus pueblos.

\section{¿Es possible la integración sin un sentido político?}

A pesar de que los procesos de integración han pasado a constituirse en una demanda urgente e indispensable en el contexto de la globalización, no existe una verdadera voluntad política en Centroamérica para considerar la integración como un medio para la inserción a los mercados mundiales.

La integración centroamericana es institucionalmente compleja y diversa. Existe un discurso integracionista con abundantes promesas que políticamente tienen bajos niveles de concreción pues en la práctica carecen de contenidos reales. No hay voluntad política para la conformación de normas e institucionalidad supranacionales de carácter vinculante.

Problemas fronterizos (como el actual problema entre Costa Rica y Nicaragua por el Río San Juan y la Isla Calero), una unión aduanera inconclusa, instituciones débiles, escasa participación de la sociedad civil y de las organizaciones no gubernamentales en los procesos de toma de decisiones, intereses individuales de cada país y no de la región en su conjunto, y la integración de diferentes grupos de poder económico dentro del mercado centroamericano, son parte de los principales desafíos que enfrenta el proceso de integración centroamericano (Segovia, op.cit.: 2). 
La región centroamericana debe desarrollar un sentido estratégico que oriente los procesos decisorios, lo que requiere el trabajo concertado para definir una agenda regional para la integración que comprenda ámbitos tan amplios como los fenómenos de corte más global, por ejemplo, los temas medio ambientales, el combate al VIH/SIDA, hasta aquellos relacionados con el mejoramiento de las políticas públicas y su administración ${ }^{5}$.

Los procesos de integración pasan actualmente por la búsqueda de un desarrollo más inclusivo que va más allá del crecimiento económico y comercial. Los discursos buscan colocar a la integración como el medio a través del cual América Latina y el Caribe pueden alcanzar objetivos políticos, sociales, económicos y culturales. Para ello los procesos de integración deben enfrentar al menos 6 paradojas (Altman Rojas Aravena, 2008: 237-271):

40 1) Aunque América Latina es hoy una región más democrática, se percibe una tendencia de la ciudadanía a sentirse progresivamente más alejada de los políticos y de la política. Hay más democracia, pero una parte cada vez mayor de la población cuestiona su capacidad de mejorar sus condiciones de vida.

41 2) Hay un mayor crecimiento del comercio con menos integración. El ámbito económico tiene su propia dinámica, más allá de los propios Estados. La dinámica de la empresa privada, lo que CEPAL ha llamado "integración real", es una integración no oficial que se da en el ámbito del mercado donde se han desarrollado procesos que poseen mucha intensidad. En ocasiones pareciera que la noción de integración regional se reduce a objetivos de liberalización comercial con intereses nacionales muy marcados, en detrimento de esfuerzos que definan una estrategia de profundización y ampliación de la integración en un sentido más amplio.

3) Hay más crecimiento económico pero los índices de desigualdad son cada vez mayores. Las reformas económicas aplicadas en la región no fueron tan exitosas como se esperaban y entre los principales problemas de América Latina siguen estando la pobreza y la desigualdad.

43 4) Existe un discurso integracionista acompañado de acciones fragmentadoras. Los Estados nacionales siguen operando en lo que toca a los procesos de integración, con los mismos papeles que tenían en el siglo XIX, reafirmando su soberanía. Ningún Estado, ni siquiera los más débiles, están por abandonar y conceder, sin compensaciones, sus capacidades de decisión soberana.

44 5) A pesar del discurso cooperativo entre los países, existe un escalamiento de tensiones que pone en evidencia el déficit institucional en la ausencia de mecanismos para la conciliación y de instituciones fuertes para la resolución de controversias cuyos fallos sean vinculantes.

6) La institucionalidad de la integración está dotada de diseños bastante complejos, con debilidades estructurales. Las características particulares por las que atraviesa actualmente América Latina, han puesto bajo especial escrutinio a las instituciones de la integración independientemente de la zona en que se encuentran. 


\section{Los desafíos del sistema de integración centroamericano (SICA)}

El proceso de integración centroamericano se reanudó con la suscripción del Protocolo de Tegucigalpa (1991). Con la decisión de los presidentes centroamericanos de avanzar hacia una reforma del SICA, se inició en Guácimo, Costa Rica (1994), un proceso de modernización y perfeccionamiento de los mecanismos de integración regionales, que fue ratificado en 1997 en Panamá. Uno de los principales objetivos de estas acciones era la constitución de la Unión Centroamericana ${ }^{6}$ (Managua, 1997), que aún está pendiente.

Esta reforma permitió una nueva base institucional para que durante los noventas se firmaran una serie de acuerdos que fueron sumando conceptual y programáticamente para que en Centroamérica se facilitara un modelo de integración abierta, enfocado hacia una creciente apertura a los mercados internacionales y que permitiera ampliar los espacios económicos e incrementara el comercio intrarregional y el desarrollo de las economías de escala, que permitiera a todos los países del Istmo una inserción más competitiva en los mercados internacionales.

Algunos de los acuerdos más importantes fueron, la Alianza para el Desarrollo Sostenible (ALIDES) firmada en Guácimo, Costa Rica (1994); el Tratado de Integración Social (San Salvador, 1995); el Tratado de Seguridad Democrática (San Pedro Sula, 1995). Todos ellos propiciaron un buen ambiente para los nuevos avances, pero, de igual manera, implicaron una serie de nuevos desafíos para la integración subregional.

La restauración de la democracia en la región tuvo como resultado el que para los años noventa todos los países centroamericanos contaran con gobiernos civiles, democráticamente electos, y con altos grados de legitimidad. Asimismo se dio una reducción del personal y del gasto militar, y se facilitó en todos los países del Istmo la creación de organismos como las Defensorías de los Habitantes para velar por la protección de los derechos humanos de la ciudadanía.

En la actualidad los problemas en torno a la gobernabilidad y la estabilidad del sistema político señalan que, aunque éstos ya no pasan por la amenaza militar, los regímenes democráticos de la región enfrentan una serie de nuevos desafíos, especialmente las fuertes debilidades en ámbitos relacionados con el imperio de la ley, la efectividad de los gobiernos y la corrupción. Este tipo de debilidades ha traído, entre otras cosas, problemas más serios y recurrentes en todos los países de la región, como por ejemplo los altos índices de abstencionismo en los procesos electorales, como se refleja en el Cuadro 6.

Cuadro 6: Participación en las Elecciones Presidenciales (En términos porcentuales)

\begin{tabular}{|l|l|l|}
\hline & Año de la elección & $\%$ de Participación \\
\hline \multirow{3}{*}{ Costa Rica } & 2006 & $65,2 \%$ \\
\cline { 2 - 3 } & 2010 a) & $69,1 \%$ \\
\hline \multirow{2}{*}{ El Salvador } & 2004 & $66.2 \%$ \\
\cline { 2 - 3 } & 2009 & $61,9 \%$ \\
\hline
\end{tabular}




\begin{tabular}{|l|l|l|}
\hline \multirow{4}{*}{ Guatemala } & 2003 (1 vuelta)a) & $57,9 \%$ \\
\cline { 2 - 3 } & 2003 (2 vuelta)a) & $46.8 \%$ \\
\cline { 2 - 3 } & 2007 & $48,1 \%$ \\
\hline \multirow{3}{*}{ Honduras } & 2005 & $55,1 \%$ \\
\cline { 2 - 3 } & 2009 a) & $49,9 \%$ \\
\hline \multirow{2}{*}{ Nicaragua } & 2001 & - \\
\cline { 2 - 3 } & 2006 a) & $61,2 \%$ \\
\hline Panamá & 2004 & $76,9 \%$ \\
\hline & 2009 & 74,0 \\
\hline
\end{tabular}

Datos tomados de los sitios oficiales en Internet de los organismos encargados de las elecciones en cada país

Fuente: IDEA, "Voter Turnout". < http://www.idea.int/vt/ > Accesado el 10 de mayo de 2011.

51 Mientras que la mayoría de los latinoamericanos apoya que la democracia es el mejor sistema de gobierno, un porcentaje alto de la población está insatisfecho con las democracias centroamericanas en la práctica. El Gráfico 1 compara ambas variables.

Gráfico 1: Centroamérica: Evolución anual entre el apoyo y la satisfacción con la democracia (2000-2010) (En términos porcentuales)

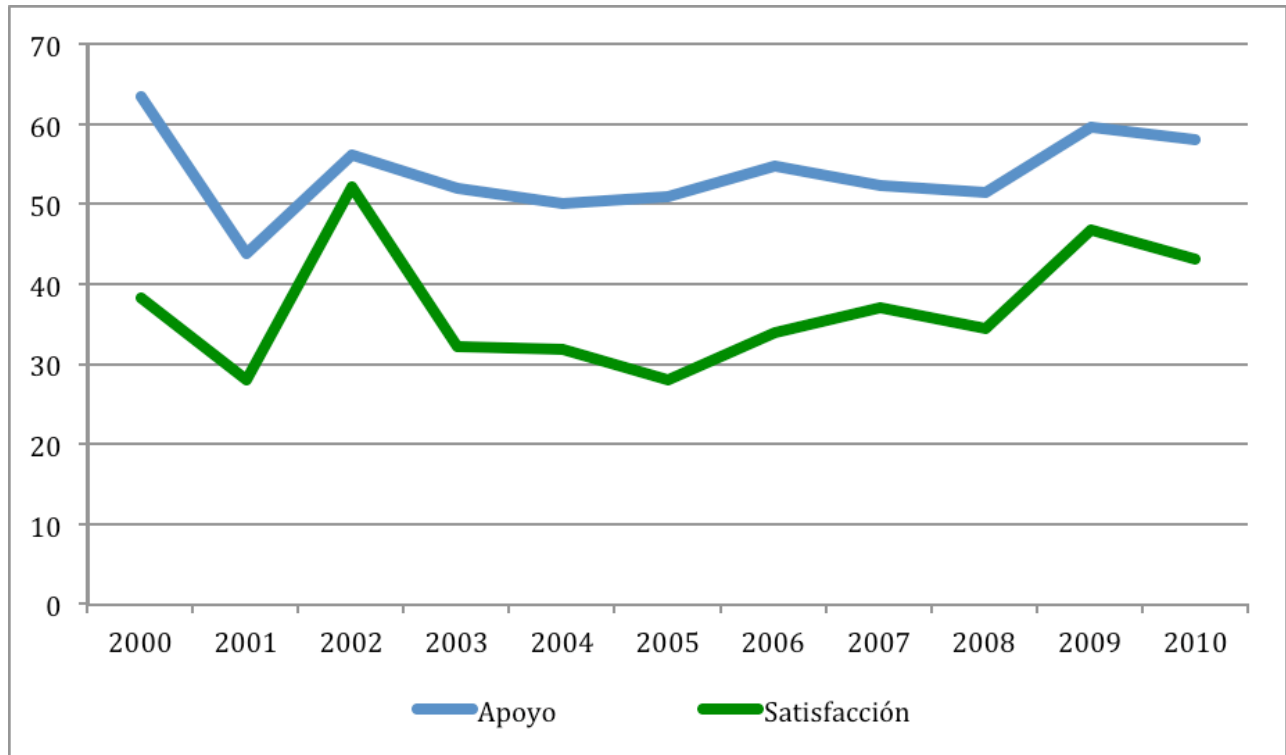

Fuente: Corporación Latinobarómetro, Informe Latinobarómetro 2010, Santiago de Chile: Corporación Latinobarómetro, 2010, pp. 43 y 47. < http://www.latinobarometro.org/latino/LATContenidos.jsp > Accesado el 10 de mayo de 2011.

52 Cabe señalar entonces, que en el campo político la región centroamericana tiene por delante grandes retos y los países deben realizar importantes esfuerzos a nivel nacional para fortalecer sus sistemas democráticos, que vuelvan a generar la confianza de sus 
poblaciones. Todo ello con el fin de mantener y consolidar aún más los avances que, desde Esquipulas se han logrado en este campo. Igualmente, la estabilidad democrática representa un requisito sumamente importante en los avances de los procesos de integración regional, por lo que estos desafíos se convierten también en retos del SICA.

En otro orden de cosas, el SICA enfrenta en el nivel político- institucional una serie de retos que tienen que ver con el logro del consenso y de acuerdos de corte comunitario. El marco jurídico y político debe ser mejorado con el fin de que cada acuerdo sea suscrito y ratificado por todos los Estados miembros. De igual forma, existen dentro del SICA instituciones bastante débiles y sin posibilidades de que sus acuerdos sean vinculantes, como son el Parlamento Centroamericano, al cual no pertenece ni Costa Rica, ni República Dominicana, y la Corte Centroamericana de Justicia de la cual Costa Rica y Panamá no forman parte. Esto dificulta los avances que pueda tener el sistema de integración puesto que las medidas tomadas por estos órganos son de alcance limitado por haber países que no se encuentran suscritos a ellos, y, que por tanto, no tienen responsabilidades con respecto a los mismos. La existencia de acuerdos e instituciones en donde no estén incluidos todos sus miembros refleja la falta de logro de consenso entre los países miembros, en la medida en que posiciones muy distintas entre unos y otros en relación con ciertos temas no logran resolverse. No obstante, lo esencial para la institucionalidad centroamericana es consolidar su legitimidad y mecanismos de transparencia a lo interno de las propias instituciones, para impulsar y decidir en forma vinculante.

Otro reto tiene que ver con la cantidad de órganos e instituciones con las que cuenta ${ }^{7}$. En esta área se hace necesario fortalecer la coordinación y reducir la dispersión, teniendo especial cuidado con la efectividad, necesidad y capacidad de acción de ciertos organismos e instituciones.

Las negociaciones políticas del SICA han sido, hasta el momento, de corte intergubernamental. Es decir, han dependido del acuerdo entre los diferentes gobiernos de los países miembros, lo cual implica que no existe un peso considerable en los órganos de tipo comunitario, ni en los acuerdos de corte supranacional, ni existen niveles profundos de integración.

57 Con respecto a elementos de corte social, la integración centroamericana debe enfrentar dos desafíos puntales; por un lado mejorar la calidad de vida de la ciudadanía $\mathrm{y}$, por otro asegurar una mayor participación de la sociedad en los procesos y la toma de decisiones con el fin de lograr una mayor legitimidad y apoyo a los gobiernos.

La calidad de vida de la mayoría de los centroamericanos no ha mejorado sustancialmente en los veinte años de democratización, la ciudadanía aún se sigue sintiendo excluida de los procesos de toma de decisiones y más insegura debido al incremento del crimen organizado. Este último problema ha adquirido dimensiones tales que los centroamericanos actualmente señalan como sus principales amenazas la delincuencia y el narcotráfico, tal como se aprecia en el Gráfico 2. 
Gráfico 2: Centroamérica: ¿Diría usted que la delincuencia y el narcotráfico son una amenaza...? (En términos porcentuales los que creen que son "algo importantes" más los que creen que son "muy importantes")

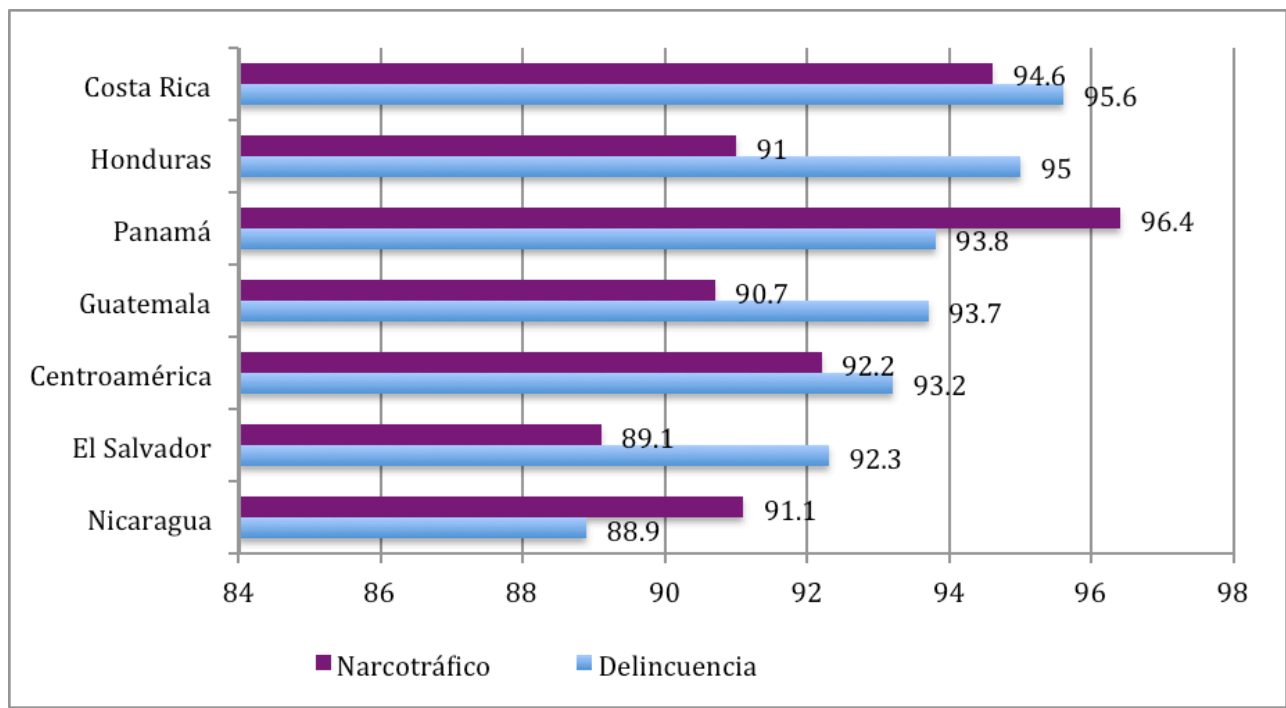

Fuente: FLACSO, Estudio de opinión pública en Latinoamérica 2009-2010, San José, Costa Rica:

FLACSO/IPSOS/AECID, 2010, pp. 100 y 102. <http://www.flacso.org/publicaciones/flacso-ipsos-final/ > Accesado el 10 de mayo de 2011.

Pese a que se han logrado reducir las diferencias en los ritmos de crecimiento y de estabilidad económica entre los países del sub esquema, con respecto a la desigualdad del ingreso no se ha corrido con la misma suerte por lo que los objetivos de integración deben ampliarse más poniendo cuidado en la esfera social.

\section{Crecimiento del comercio intraregional}

En el contexto económico el comercio en el MCCA ha ido creciendo en los últimos años. Aunque las exportaciones disminuyeron en 2001 y 2002 producto de la caída del precio de las mismas, a partir del 2003 la tasa promedio de crecimiento anual se ha incrementado. Para el período 2003-2008 la tasa de crecimiento anual fue de 13,3\% (SIECA, estado op.cit.). Aunque cabe destacar que entre 2008 y 2009 las exportaciones disminuyeron (SIECA, sistema, 2009).

61 Entre los productos exportados sobresalen aquellos de tipo manufactureros, especialmente de tecnología media y alta, y los productos agrícolas los cuáles han tendido a la diversificación debido al deterioro de los precios de productos tradicionales como el café, el azúcar y el banano.

Por su parte, las importaciones también han aumentado con una tasa de crecimiento promedio anual del 15,3\% durante el periodo 2003-2008 (SIECA, estado op.cit.). No obstante, las importaciones también descendieron en 2009, producto de la crisis (SIECA, sistema, 2009). Esta situación ha llevado a que se presente un déficit en la balanza comercial a lo largo del periodo, como se puede apreciar en el Cuadro 8.

Esto se explica por el hecho de que el proceso de reestructuración de la oferta exportable ha venido acompañado de una clara dependencia de las importaciones: tanto los productos generados bajo la modalidad de maquila como aquellos con componentes importantes de conocimiento (como en el caso de las exportaciones de 
INTEL en Costa Rica) e incluso el turismo, dependen en gran medida de las importaciones. Esta reestructuración de la oferta exportable ha transformado el rol de la subregión en los procesos productivos mundiales donde se deja la especialización de aquellos procesos nacionales que llevan a productos finales -como en los tiempos de la economía agropecuaria- y se pasa a ser parte de un proceso multinacional de producción integrado.

Cuadro 8 : Centroamérica: Balanza Comercial 2001-2009

\begin{tabular}{|l|l|l|l|l|l|l|l|l|l|l|}
\hline & 2001 & 2002 & 2003 & 2004 & 2005 & 2006 & 2007 & 2008 & 2009 & $2010 \mathrm{a})$ \\
\hline Costa Rica & -74 & -593 & -313 & -564 & -1026 & -1403 & -1251 & -2812 & 151 & -1047 \\
\hline El Salvador & -2183 & -2105 & -2394 & -2739 & -3187 & -3671 & -4395 & -4978 & -3270 & -3800 \\
\hline Guatemala & -2165 & -2893 & -3183 & -3937 & -4623 & -5330 & -5797 & -5851 & -3671 & -4595 \\
\hline Honduras & -935 & -827 & -1182 & -1497 & -1725 & -2420 & -3392 & -4362 & -2613 & -2835 \\
\hline Nicaragua & -1051 & -1068 & -1090 & -1211 & -1441 & -1586 & -1941 & -2420 & -1625 & -1772 \\
\hline
\end{tabular}

a) Números preliminares.

Fuente: Datoa de 2001-2007 tomados de CEPAL, "CEPALSTAT. Balanza de pagos". < http:// websie.eclac.cl/sisgen/Consultalntegrada.asp?

idAplicacion=6\&idTema=119\&idIndicador=1502\&idioma $=>$ Accesado el 20 de setiembre de 2010 y datos de 2008-2010 tomados de CEPAL, Balance preliminar de las economías de América Latina y el Caribe 2011, Santiago, Chile: CEPAL, 2011, p. 154. <http://www.eclac.org/publicaciones/xml/ 8/41898/2010-975-BPE-Book-WEB_3-2-11.pdf > Accesado el 10 de mayo de 2011.

Como principal socio comercial de estos países se encuentra Estados Unidos. En 2008, Estados Unidos representó un 31,6\% de las exportaciones regionales y un 33,4\% de las importaciones. En segundo lugar están los países centroamericanos, es decir, el comercio intra regional $(29,4 \%$ de las exportaciones y $12,7 \%$ de las importaciones totales), superando a la Unión Europea quien constituye el tercer socio comercial.

Cuadro 9: Centroamérica: Principales socios comerciales de la región 2008

\begin{tabular}{|l|l|l|l|l|}
\hline & \multicolumn{2}{|l|}{ Exportaciones } & \multicolumn{2}{l|}{ Importaciones } \\
\hline & $\%$ & US \$ Millones & $\%$ & US \$ Millones \\
\hline Estados Unidos & 31,6 & 6849 & 33,4 & 16160 \\
\hline MCCA & 29,4 & 6373 & 12,7 & 6122 \\
\hline Unión Europea & 13,2 & 2856 & 8,8 & 4281 \\
\hline
\end{tabular}

Fuente: SIECA, Estado de Situación de la Integración Económica Centroamericana 2009, op. cit., p. 6.

El comercio intra-MCCA ha tenido mucha importancia en la subregión desde la creación del Mercado Común Centroamericano en 1960, con excepción del periodo 1980-1985. 
Desde su inicio hasta el 2008 se pasó de US\$30,3 millones de dólares a US\$ 6373,3 millones con una tasa promedio de crecimiento anual de $11,8 \%$.

Cabe señalar que el aumento en el comercio intrarregional tiene relación con los avances que en este sentido se han logrado en el sub esquema, siendo uno de los más importantes la conformación de una unión aduanera cuya cobertura arancelaria actual es muy alta (95\%).

El gran dinamismo del comercio intrarregional ha traído beneficios al sub esquema debido a las numerosas empresas centroamericanas que tienen operaciones relacionadas directamente con éste, de las cuales, aproximadamente, un $75 \%$ son pequeñas y medianas empresas lo cual deriva en fuentes de trabajo y el impulso a una nueva clase empresarial, entre otros.

No obstante los resultados positivos señalados, se debe tener en cuenta que el comercio intra región no ha sido igual para todos los países: Guatemala es el mayor exportador (36\%), Honduras el mayor importador (28\%), Honduras y Nicaragua son los que menos venden en la región ( $9 \%$ y $8 \%$ respectivamente) y Costa Rica, que a pesar de ser el segundo vendedor, es el que menos compras realiza en Centroamérica (9\%).

Cuadro 10: Centroamérica: Comercio intrarregional (En términos porcentuales)

\begin{tabular}{|l|l|}
\hline Exportaciones & Importaciones \\
\hline Guatemala: $36 \%$ & Honduras: $28 \%$ \\
\hline Costa Rica: $24 \%$ & El Salvador: $25 \%$ \\
\hline El Salvador: $23 \%$ & Guatemala: $24 \%$ \\
\hline Honduras: $9 \%$ & Nicaragua: $14 \%$ \\
\hline Nicaragua: $8 \%$ & Costa Rica: $9 \%$ \\
\hline
\end{tabular}

Fuente: SIECA, Estado de Situación de la Integración Económica Centroamericana 2009, op. cit., p. 13.

Aún así persiste una marcada dependencia al mercado estadounidense, lo que explica porque Centroamérica (además de México) fueron los países más afectados por la crisis económica de 2008 y 2009, lo que obliga al SICA a examinar nuevas opciones de negociación con el fin de no verse afectado tan considerablemente por lo ciclos económicos de este país.

70 Esta situación se observa claramente también respecto a la Inversión Extranjera Directa (IED) en la región la cual en los primeros años de la década tuvo un importante decrecimiento debido en gran parte a que la mayoría de esta inversión tiene como destino las actividades manufactureras sobre todo para abastecer las necesidades estadounidenses, de modo que la contracción económica tuvo un efecto evidente en la IED que entraba a la subregión. A partir de 2003 se produjo un crecimiento de la misma como resultado de la coyuntura internacional positiva. Sin embargo, nuevamente disminuyó desde finales de 2008 y a lo largo de 2009 por los efectos de la crisis financiera internacional. 
71 En este sentido el sector de mayor dinamismo en la subregión ha sido el de servicios especialmente con la llegada a la región de empresas como Wall-Mart (en todos los países del MCCA) y América Móvil (en El Salvador).

\section{Integralidad de la integración}

La integración centroamericana ha tenido importantes avances en los ámbitos económico y comercial. El comercio intra-región tiene un peso importante para todos los países del Istmo, y los acuerdos logrados en materia comercial tuvieron como resultado que Centroamérica fuera la primera subregión latinoamericana en firmar un Acuerdo de Asociación con la Unión Europea.

Sin embargo, en otros ámbitos los avances no han sido tan positivos. Es necesario comprender que para que muchos de los acuerdos y compromisos establecidos por los Estados tengan un impacto concreto y positivo se debe definir el grado de integración que se pretende alcanzar. Un proceso de integración multidimensional requiere que se defina el escenario comunitario y para esto es fundamental lograr la cohesión social tanto intra como entre los Estados ${ }^{8}$.

La cohesión social, entendida como la dialéctica entre mecanismos instruidos de inclusión y exclusión social y las respuestas, percepciones y disposiciones de la ciudadanía frente al modo en que ellos operan (CEPAL, 2007: 16); se relaciona con todos aquellos factores que amenazan la estabilidad de la región y con el bienestar de los ciudadanos y las ciudadanas. Ejemplo de esto es que más de la mitad considera que el conflicto entre personas de distintas etnias es muy fuerte, que sólo un $43 \%$ considera que existe igualdad de oportunidades sin importar el origen, que un $79 \%$ considera que la distribución de la riqueza en su país es injusta, que un $74 \%$ considera que el conflicto entre ricos y pobres es muy fuerte y que un $69 \%$ considera que el conflicto entre trabajadores y empresarios es muy fuerte.

Cuadro 11: Centroamérica: algunos indicadores de cohesión social (En términos porcentuales los que están muy de acuerdo con las siguientes frases)

\begin{tabular}{|l|l|l|l|l|l|}
\hline País & $\begin{array}{l}\text { El conflicto } \\
\text { entre } \\
\text { personas de } \\
\text { distintas } \\
\text { etnias es muy } \\
\text { fuerte }\end{array}$ & $\begin{array}{l}\text { Existe igualdad de } \\
\text { oportunidades sin } \\
\text { importar origen }\end{array}$ & $\begin{array}{l}\text { La distribución } \\
\text { de la riqueza } \\
\text { en su país es } \\
\text { injusta }\end{array}$ & $\begin{array}{l}\text { El ponflicto ricos } \\
\text { yntres es } \\
\text { muy fuerte }\end{array}$ & $\begin{array}{l}\text { El conflicto } \\
\text { entre } \\
\text { empresarios y } \\
\text { trabajadores es } \\
\text { muy fuerte }\end{array}$ \\
\hline Costa Rica & 65 & 54 & 71 & 77 & 72 \\
\hline El Salvador & 55 & 38 & 76 & 77 & 73 \\
\hline Guatemala & 53 & 32 & 86 & 65 & 59 \\
\hline Honduras & 50 & 41 & 81 & 76 & 67 \\
\hline Nicaragua & 52 & 51 & 82 & 76 & 75 \\
\hline
\end{tabular}




\begin{tabular}{|l|l|l|l|l|l|}
\hline Centroamérica & 55 & 43 & 79 & 74 & 69 \\
\hline
\end{tabular}

Fuente: Corporación Latinobarómetro, Informe Latinobarómetro 2009, Santiago de Chile: Corporación Latinobarómetro, 2009, p. 42. < http://e-lecciones.net/archivos/loultimo/ LATINOBAROMETROlite\%202009.pdf >Accesado el 15 de abril de 2010 y Corporación

Latinobarómetro, Informe Latinobarómetro 2007, Santiago de Chile, Corporación Latinobarómetro, 2008, pp. 65, 67 y 70. < http://www.der.oas.org/INFORME\%20LB\%202007.pdf > Accesado el 15 de abril de 2010.

Unido a lo anterior, el Gráfico 3 muestra los niveles de tolerancia entre distintos grupos en Centroamérica. La menor tolerancia se da entre ricos y pobres y hacia las personas con diferente preferencia sexual (sólo el 39,0\% y el 39,9\% respectivamente señalan que se practica la tolerancia). Seguidamente está la tolerancia entre personas de distinta etnia y entre personas de distinto credo religioso, pero estos presentan porcentajes moderadamente mayores de tolerancia ( $62,2 \%$ y $64,2 \%$ respectivamente).

Gráfico 3: Centroamérica: Niveles de tolerancia (2009) (En términos porcentuales los que creen que se practica la tolerancia "siempre" más "casi siempre")

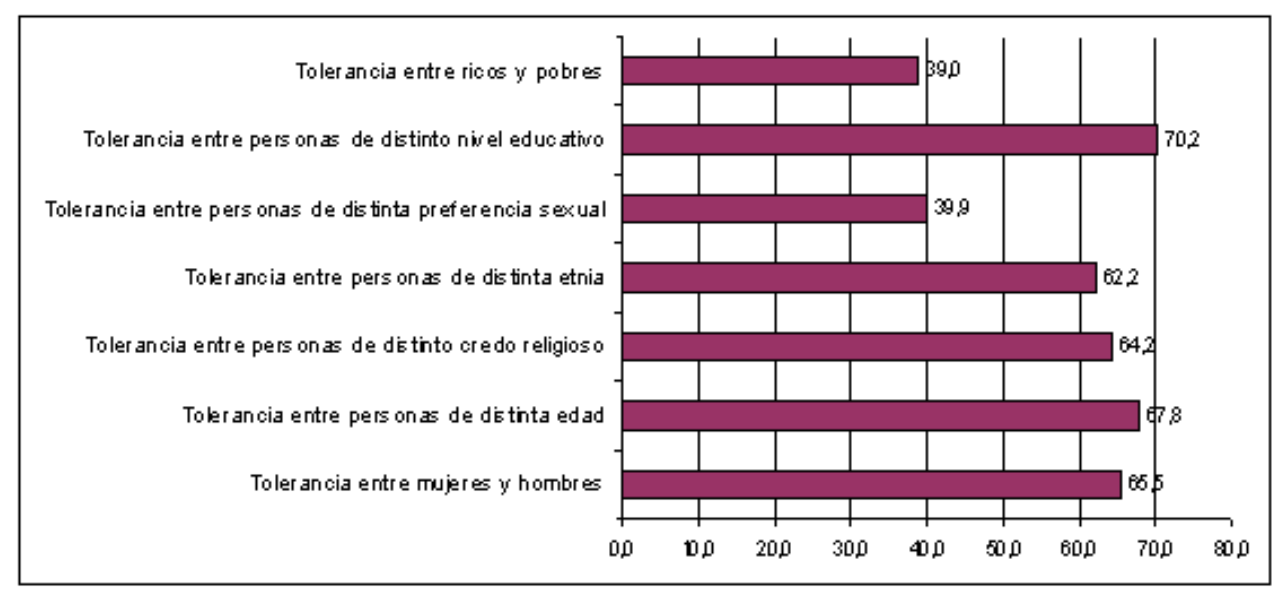

Fuente: FLACSO, Estudio de opinión pública en Latinoamérica 2009-2010, op. cit., pp. 78-81.

Una perspectiva multidimensional de la integración centroamericana requiere entonces del trabajo en ámbitos más allá de lo económico que busquen mejorar la distribución de la riqueza, la igualdad de oportunidades, el sentido de pertenencia de los ciudadanos, la convivencia democrática y el respeto a la "diferencia". Resulta de suma importancia en el caso de Centroamérica el tema de la inclusión y respeto de los pueblos indígenas, así como los avances que desde una perspectiva regional se puedan realizar.

\section{Centroamerica en el mundo}

\section{El ALBA en Centroamérica ${ }^{9}$}

La Alternativa Bolivariana para los pueblos de Nuestra América (ALBA) es una propuesta de integración planteada en diciembre de 2001, en Isla Margarita, por el gobierno venezolano como respuesta al Área de Libre Comercio para las Américas (ALCA) propuesto en Miami durante la Cumbre de las Américas en 1994. El ALBA expone 
una visión alternativa a los acuerdos de libre comercio fundamentada en tres principios: (1) oposición a las reformas de libre mercado; (2) no limitar la acción reguladora del Estado en beneficio de la liberalización económica; y (3) armonizar la relación Estado-mercado.

La visión del presidente venezolano Hugo Chávez sostiene que, si bien los países de América Latina coinciden en los fundamentos de la integración regional, carecen de una estrategia adecuada para implementarla, además de la necesidad de que los proyectos de integración "dejen de servir al imperialismo y a las oligarquías nacionales" y pasen a ser un instrumento para el desarrollo económico de los sectores sociales de los pueblos latinoamericanos ${ }^{10}$.

79 Este discurso que relaciona al ALBA con una alternativa para "los pueblos" flexibiliza su adhesión. Independientemente de las subregiones $u$ otros compromisos que cada gobierno haya adquirido, la pertenencia al ALBA no supone un obstáculo para los avances en otros proyectos de integración. Muestra de ello es Nicaragua, que siendo miembro pleno del ALBA, mantiene vigente el Tratado de Libre Comercio con Estados Unidos. Sin embargo en la práctica el fuerte carácter ideológico de la propuesta ha llevado a importantes divisiones y conflictos a lo interno de los países, así como entre algunos Estados de la región.

Ejemplo del primer caso es el de Honduras cuyo ex presidente Manuel Zelaya suscribió, el 25 de agosto de 2008, la adhesión de su país al ALBA pese a las fuertes protestas que desde sectores tanto empresariales como del Congreso hondureño ocasionó tal firma (La Nación, 2008). El presidente Zelaya expresó ante empresarios hondureños que la idea de adherirse al ALBA surgió como respuesta a la falta de dinero. Mientras el Banco Mundial ofreció prestar a Honduras US $\$ 10$ millones, el gobierno venezolano ofreció un préstamo de US $\$ 130$ millones al incorporarse el país al ALBA (Laínez, 2008). Este vínculo -más económico que político- se observa también en el hecho de que la ratificación por parte del Congreso hondureño a la incorporación de ese país al ALBA el 9 de octubre de 2008, pasó con una serie de restricciones relacionadas con el uso de recursos económicos y el descarte de compromisos militares y políticos. Finalmente, luego del golpe de Estado en Honduras y con el inicio del nuevo gobierno, el Congreso de Honduras separó al país del ALBA en enero de 2010.

81 Respecto a los conflictos y roces que el incorporarse al ALBA puede causar a nivel regional se encuentra, entre otros, el anuncio en enero de 2008 de que ante una hipotética agresión de los Estados Unidos a Venezuela, los países miembros del ALBA realizarían una alianza militar. En esa ocasión el presidente de Venezuela Hugo Chávez junto al mandatario nicaragüense Daniel Ortega estuvieron de acuerdo en señalar que si Estados Unidos "tocaba" alguno de los miembros del ALBA, sería "como si se metiese con todos". Sin embargo, el enfrentamiento de Venezuela a Estados Unidos ha sido más efectivo en la teoría que en la práctica. La realidad es que el petróleo venezolano sólo puede ser procesado en refinerías especiales, la mayoría de las cuales están en Estados Unidos (Romero Corrales, 2010: 238) De ahí que Venezuela no pueda romper completamente sus relaciones con Estados Unidos.

Por su parte Petrocaribe se ha convertido en la expresión de la aplicación de la política del ALBA para la administración de los recursos energéticos. La escala de financiamiento de la factura petrolera tomando como referencia el precio del crudo es muestra de ello. Si la factura supera los 50 dólares por barril, por ejemplo, el porcentaje de ésta que se financia es el $40 \%$, el período de pago se extiende a 25 años y se reduce el 
interés al 1\%; y si el pago es a corto plazo, se extiende el período de 30 a 90 días (Altman, op.cit.: 139).

Actualmente Nicaragua, Guatemala y Honduras forman parte de Petrocaribe. El contexto mundial del alza en los precios de los hidrocarburos ha tenido como resultado que muchos países de la región estén volcando su mirada a esta iniciativa. En el caso de Costa Rica y a pesar de los roces que ha tenido en el pasado con el presidente Chávez por las diferencias ideológicas entre ambos, el ex presidente Oscar Arias presentó formalmente la petición de incorporarse. Al igual que en casos anteriores, en este caso se vuelve a observar cómo la cercanía a los proyectos bolivarianos causan controversia pues existen diversos grupos costarricenses que han llamado a tener cautela respecto a las implicaciones que este tipo de incorporaciones podrían traer (La Nación, editorial, 2008). Petrocaribe no ha admitido formalmente a Costa Rica. Ante esta situación, la actual Presidenta Laura Chinchilla afirmó que no insistirá en el ingreso a Petrocaribe, sino que prefiere apostar por disminuir la dependencia petrolera mediante la inversión en energías limpias (Murillo, 2010).

\section{Centroamérica y los Tratados de Libre Comercio}

84 Como parte de la estrategia centroamericana de apertura económica, y luego de la formación del MCCA, los países centroamericanos se dieron a la tarea, a partir de la década de los noventa, de establecer otros procesos de integración y acuerdos comerciales con países fuera del Istmo. Es así como la región en su conjunto y algunos países en particular comienzan a suscribir Tratados de Libre Comercio con México, Chile, Taiwán, Canadá, República Dominicana, Panamá y la Comunidad del Caribe (CARICOM). Sin embargo la suscripción del Tratado de Libre Comercio entre Centroamérica- Estados Unidos y República Dominicana (CAFTA-DR por sus sigla en inglés) y del Acuerdo de Asociación Estratégica con la Unión Europea vienen a ser el punto máximo de este proceso (Osterlof Villasuso, op.cit.).

Respecto a estos procesos de apertura comercial se ha creado una serie de controversias, especialmente respecto a lo que refiere al CAFTA- DR(Rojas Aravena Solis Rivera, 2006). La firma de este tratado estuvo marcada por conflictos entre diversos sectores que veían amenazadas algunas de sus condiciones, sobre esto resalta el caso de Costa Rica cuya ratificación fue puesta a consulta popular mediante un referendo realizado en octubre de 2007 en donde se votó a favor de la ratificación pero que sin embargo, resultó difícil de poner en vigencia por las dificultades en torno a la aprobación de una Agenda Complementaria al tratado.

EL CAFTA-DR ha llevado a que muchos analistas se pregunten si se convertirá en un motor o un obstáculo para los procesos de integración regional. La armonización de las normas y compromisos acordados intra región como de ésta con Estados Unidos constituye un desafío para el avance del SICA.

Otro reto se refiere a las asimetrías existentes entre éstos y Estados Unidos. El papel de los Estados nacionales junto a los esfuerzos subregionales debe ahora más que nunca apuntar a los esfuerzos de cohesión social y de llevar la integración a niveles más profundos.

88 En suma, al existir en la región gran cantidad de acuerdos comerciales bilaterales entre países o desde el bloque que no siempre son compatibles y muestran escasos resultados positivos, Centroamérica deberá de idear la forma para avanzar en su propio proceso de 
integración de la mano de su apertura al mundo. Asimismo, sigue vigente la crítica que se le hace al regionalismo abierto latinoamericano, tachado por algunos gobiernos de mantener una inclinación neoliberal, y de ser un regionalismo ligero que emana de concepciones clásicas de soberanía, donde se rechaza una institucionalidad fuerte y la supranacionalidad para trabajar dentro de un marco intra gubernamental.

\section{Centroamérica y la Unión Europea"1}

En el caso de las negociaciones para suscribir un Acuerdo de Asociación entre la Unión Europea y el SICA a los desafíos anteriores se les debe agregar el hecho de que la Unión Europea plantea como exigencia para negociar una visión y voz de bloque, hecho que supone un inmenso desafío para una región cuyas élites no han sido capaces de compartir una visión del desarrollo y de la democracia (Solis, 2008).

Desde el anuncio oficial de las negociaciones la región se ha venido enfrentando a diferencias no sólo en el enfoque de negociación, sino además a una arquitectura institucional bastante débil en temas supranacionales. Además los tres ámbitos que forman parte del Acuerdo de Asociación (libre comercio, diálogo político y cooperación para el desarrollo) exigen que Centroamérica tenga como una de sus prioridades la cohesión social para lo cual necesitará la adopción de agendas sociales y económicas que se complementen y refuercen en los ámbitos nacionales y regionales, más el fortalecimiento de la integración para que ésta sea un instrumento de desarrollo.

Pese a estos desafíos, el proceso de negociación culminó con éxito. Luego de VIII rondas de negociación, el Acuerdo de Asociación CA-UE fue suscrito en mayo de 2010. Centroamérica fue el primer bloque subregional, y hasta el momento el único bloque, en firmar el Acuerdo de Asociación con la Unión Europea. Los problemas internos al interior de la Comunidad Andina (CAN) obligaron a la firma de acuerdos bilaterales sólo con Perú y Colombia y en el caso de MERCOSUR, las negociaciones están estancadas desde 2004.

\section{Centroamérica y Asia-Pacífico}

Finalmente, la región de Asia Pacífico adquiere cada vez mayor importancia para los países de América Latina en general. Las relaciones comerciales con esa región, principalmente con China, permitieron una recuperación más rápida luego de la crisis financiera internacional. No obstante, América Latina en general y Centroamérica en particular no han generado una clara estrategia que les permita posicionarse mejor en sus nexos birregionales con Asia Pacífico, los avances se han dado principalmente de manera individual/bilateral. Otra forma en que se han venido desarrollando las relaciones en los últimos 20 años se efectúa por medio de la membresía de algunos países de la región en foros transpacíficos como el Foro de Cooperación Económica Asia Pacífico (APEC) y el Foro de Cooperación de América Latina-Asia del Este (FOCALAE).

APEC ha sido el más relevante, pero ninguno de los países centroamericanos ha logrado insertarse en ese foro, proceso actualmente difícil debido a la moratoria vigente que bloquea el acceso de nuevos miembros. En este sentido, la iniciativa que representaba una mejor oportunidad para Centroamérica es el Foro del Arco del Pacífico Latinoamericano. Este fue creado en 2006 a iniciativa del gobierno de Perú y estaba conformado por 11 economías latinoamericanas (México, Guatemala, Honduras, El 
Salvador, Nicaragua, Costa Rica, Panamá, Colombia, Ecuador, Perú y Chile) (OIRLA, 2009).

El objetivo era profundizar la relación comercial entre los países de la iniciativa y profundizar la relación de todo el bloque con los países de Asia Pacífico. Labores concretas que promovieron en este sentido son la convergencia de acuerdos comerciales ya existentes, el fortalecimiento de la eficiencia de las uniones aduaneras, la cooperación económica y técnica, entre otros.

Una de las principales limitaciones del Arco era que a pesar de su orientación abierta existía poca articulación entre los países. Las cuatro economías de mayor tamaño (Chile, Colombia, México y Perú) representan más del $90 \%$ del intercambio comercial con la ASEAN + 3 (CEPAL, 2010). En el caso de Centroamérica, sólo Costa Rica ha generado relaciones importantes con el Asia Pacífico, actualmente China es su tercer mercado de exportación más importante (Ibid.:12). Esta puede ser una de las razones por las cuales el Arco del Pacífico se transformó en Alianza del Pacífico en abril de 2011. Esto significó un cambio en su conformación, pues sólo permanecieron las economías más grandes: Colombia, México, Perú y Chile. En este contexto, es de mayor importancia aún que los países centroamericanos generen una política común para acercarse a Asia Pacífico.

\section{Reflexiones finales}

96 A manera de conclusión, se pueden señalar una serie de importantes desafíos para la región y la integración de Centroamérica como medio para lograr el desarrollo regional. Un primer desafío son las asimetrías entre los países y a lo interno de éstos. Por ejemplo, con respecto al desarrollo humano están por un lado los países del Sur (Panamá y Costa Rica) con un índice de desarrollo humano alto. Y por otro lado, están los países del CA4 (El Salvador, Guatemala, Nicaragua y Honduras con un índice de desarrollo humano medio-bajo). Esto, más la debilidad de las instituciones, partidos políticos débiles y una elite política con altos grados de deslegitimación, son factores que alertan y preocupan a los estudiosos de la región que, incluso comienzan a referirse a las "dos Centroaméricas", la Centroamérica del Norte (países CA4) y la Centroamérica del Sur (Costa Rica y Panamá).

97 Otro importante desafío es la ausencia de fondos de cohesión para erradicar las asimetrías. La integración europea fue un proceso gradual que permitió a países con índices de desarrollo más bajos ir subiendo paulatinamente como fueron los casos de Italia, España e Irlanda. La realidad del proceso centroamericano indica que se ha concebido y construido la Integración desde una perspectiva económica, excluyente de otros aspectos de la realidad social, encomendada a técnicos gubernamentales con poco o ningún control ciudadano. Es necesario darle un mayor peso a los componentes sociales, culturales y políticos en el proceso, de tal manera que las políticas de integración lo sean también de integralidad; de esto depende la sostenibilidad del proceso.

98 La falta de voluntad política de los gobiernos es un tercer reto a resolver. La escasa disposición de los gobiernos para otorgarle al SICA autoridad supranacional, hace que se sigan sobreponiendo las estructuras nacionales a la institucionalidad de la integración. Los Estados centroamericanos siguen operando con los mismos papeles que tenían los Estados nacionales en el Siglo XIX. La poca voluntad política de dotar con 
una institucionalidad eficaz al sistema de integración ha generado dinámicas de mucha intensidad donde la empresa privada realiza la "verdadera integración", una integración no oficial inmersa en el ámbito del mercado, en el ámbito económico donde el Estado tiene un papel menor en el proceso. Es cierto que en las áreas económicas, financieras y aduaneras la región centroamericana ha tenido una integración mayor, pero renunciando al plano político de la misma.

La debilidad de las instituciones de la integración es un cuarto elemento que desafía el proceso mismo del bloque centroamericano. No sólo no hay voluntad política para ceder autoridad al SICA, sino que de suceder esto, el mismo organismo no estaría en capacidad de responder adecuadamente a ello. Es un círculo vicioso en donde los gobiernos no ceden autoridad a la institucionalidad de la integración, que a su vez debilita a las instituciones, que a su vez tratan de operacionalizar el sistema sin mucho éxito.

La falta de decisiones vinculantes es uno de los principales problemas de la integración, pues no se ha creado aún una forma efectiva de lidiar con los conflictos. Un ejemplo de ello es el golpe de Estado en Honduras en junio de 2009. Pese a las reuniones y debates en organismos multilaterales, no se llegó a una solución efectiva. Otro ejemplo es el caso del conflicto actual entre Costa Rica y Nicaragua por el Río San Juan y la Isla Calero. Este conflicto no hace referencia a un problema limítrofe, sino más bien a una invasión por parte del gobierno nicaragüense en territorio costarricense. Aunque los organismos multilaterales como la OEA se han pronunciado al respecto, la ausencia de una decisión vinculante ha prolongado el conflicto.

Por último, es necesario hacer un análisis tanto de los aspectos positivos, como los negativos que ha tenido hasta el momento el Tratado de Libre Comercio con los Estados Unidos (TLC-DR). La influencia de los grupos de poder económico en el proceso de integración centroamericana es significativa. Entre los aspectos positivos de dicha influencia, está su contribución al aumento de la competitividad de la región mediante la aplicación de procesos de producción más eficientes y técnicas administrativas y gerenciales modernas. Igualmente, estos grupos de poder económico están haciendo más atractiva a la región para la inversión extranjera. Asimismo, a través de sus inversiones están colaborando a la generación de empleo regional. Entre los aspectos negativos se encuentran su incidencia en la desigualdad regional y nacional por una mayor concentración de la riqueza y del poder político. Este es el escenario que enmarcó las discusiones en torno a los TLC con USA. Algunos temen que la incorporación de Centro América al tratado de libre comercio, lejos de fomentar vínculos asociativos y comunitarios entre los socios del SICA que generen una integración de "verdad", como la llama Alexander Segovia, va a consolidar un estado de "anexión" al socio mayor, en este caso EE.UU., que vendrá a suplantar dinámicas económicas intra-región por las fuerzas transnacionales.

La posibilidad de superar los retos que tiene por delante el SICA pasa por el efectivo empleo de las voluntades políticas de los países de la región. En todo caso, más allá de cualquier recomendación, la integración centroamericana continúa siendo, ante todo, una aspiración de mediano plazo cuya concreción -en términos absolutos- será previsible si se superan las diferencias de cada coyuntura particular. El proceso gradual de acercamientos y la cooperación crecientes al interior y entre los gobiernos para crear nuevos vínculos y medidas de confianza permitirán, finalmente, llevar a buen puerto el proceso de integración centroamericano. 


\section{BIBLIOGRAFÍA}

“Acuerdos de Esquipulas II", Guatemala, 7 de agosto, 1987. < http://www.acnur.org/biblioteca/ pdf/2530.pdf> Accesado el 15 de abril de 2010.

Alianza Centroamericana para el Desarrollo Sostenible (ALIDES). < http://www.ccad.ws/ antecedentes/alides/alides.htm >

Altmann Borbón, Josette (Ed), ALBA: ¿Una nueva forma de integración regional? Argentina: Editorial TESEO, 2011.

Altmann, Josette, “Alba: ¿Un Proyecto Alternativo para América Latina?” ARI. 17/2008, 8 de febrero. Real Instituto Elcano. < http://www.flacso.org/fileadmin/usuarios/documentos/Integracion/ ALBA_Un_proyecto_alternativo_para_AL.pdf >

Altmann, Josette, "El ALBA. De alternativa de integración a alianza política e ideológica". Foreign Affairs Latinoamérica, Vol. 10. No. 3, julio-setiembre, 2010, pp. 32-38.

Altmann, Josette, “El ALBA, Petrocaribe y Centroamérica: ¿intereses comunes? Nueva Sociedad No. 219, enero-febrero, 2009, pp. 127-144.

Altmann, Josette, “Las relaciones Unión Europea-América Latina: un balance de la situación actual”. Revista Española de Desarrollo y Cooperación. Número Extraordinario. Monográfico: V Cumbre entre la Unión Europea y América Latina y el Caribe, 16 de mayo, 2008, pp. 67-84.

Altmann, Josette, Rojas Aravena, Francisco y Beirute Brealey, Tatiana, “Europa-América Latina y el Caribe: ¿Bilateralidad vs Birregionalidad? Construyendo un nuevo relacionamiento estratégico." $11^{\circ}$ Foro Biarritz: Relaciones UE-AL: Dónde estamos, para dónde vamos, España, 4 y 5 de noviembre 2010.

Altmann, Josette y Rojas Aravena, Francisco, "Multilateralismo e integración en América Latina y el Caribe”. Josette Altmann y Francisco Rojas Aravena (Eds.) Las Paradojas de la integración en América Latina y el Caribe, España: Siglo XXI y Fundación Carolina, 2008, pp. 237-271.

Comisión Económica para América Latina y el Caribe (CEPAL), Balance preliminar de las economías de América Latina y el Caribe 2011, Santiago, Chile: CEPAL, 2011. <http://www.eclac.org/ publicaciones/xml/8/41898/2010-975-BPE-Book-WEB_3-2-11.pdf > Accesado el 10 de mayo de 2011.

CEPAL, Anuario Estadístico de América Latina y el Caribe 2010, Santiago de Chile: CEPAL, 2010. < http://www.eclac.org/publicaciones/xml/6/42166/LCG2483b_contenido.pdf> Accessado el 10 de mayo de 2011.

CEPAL, El Arco del Pacífico Latinoamericano: construyendo caminos de complementación e integración con Asia. Santiago de Chile: CEPAL, 2010. < http://www.eclac.org/comercio/publicaciones/xml/

3/41283/Arco_Pacifico_Latinoamericano_Complementacion_Integracion.pdf > Accesado el 26 de octubre de 2010.

CEPAL, Anuario Estadístico de América Latina y el Caribe 2009, Santiago de Chile: CEPAL, 2010. < http://www.eclac.org/cgi bin/getProd.asp?xml=/publicaciones/xml/6/38406/P38406.xml\&xsl=/ deype/tpl/p9f.xsl\&base=/tpl/top-bottom.xsl > Accesado el 20 de setiembre de 2010.

CEPAL, “CEPALSTAT. Balanza de pagos”, $2010<$ http://websie.eclac.cl/sisgen/

ConsultaIntegrada.asp?idAplicacion=6\&idTema=119\&idIndicador $=1502 \&$ idioma $=>$ Accesado el 20 de setiembre de 2010 . 
CEPAL, Cohesión Social: Inclusión y sentido de pertenencia en América Latina y el Caribe. Santiago de Chile: CEPAL/ AECID/ SEGIB, enero 2007. < http://www.oei.es/quipu/ cohesion_socialAL_CEPAL.pdf > Accesado en mayo de 2007.

Comité Consultivo-Sistema de Integración Centroamericana (CC-SICA), s.f. Propuesta estratégica para orientar el desarrollo y la integración centroamericana. Cuaderno de Trabajo, San Salvador, El Salvador, SICA.

Conferencia de las Naciones Unidas sobre Comercio y Desarrollo (UNCTAD), "Foreign Direct Investment Flows 1970-2009" 2010. < http://unctadstat.unctad.org/TableViewer/tableView.aspx? ReportId=88> Accesado el 20 de setiembre de 2010.

Corporación Latinobarómetro, Informe Latinobarómetro 2010, Santiago de Chile: Corporación Latinobarómetro, 2010. < http://www.latinobarometro.org/latino/LATContenidos.jsp > Accesado el 10 de mayo de 2011.

Corporación Latinobarómetro, Informe Latinobarómetro 2009, Santiago de Chile: Corporación Latinobarómetro, 2009. < http://e-lecciones.net/archivos/loultimo/

LATINOBAROMETROlite\%202009.pdf >Accesado el 15 de abril de 2010

Corporación Latinobarómetro, Informe Latinobarómetro 2008, Santiago de Chile: Corporación Latinobarómetro, 2009. < http://www.latinobarometro.org/docs/

INFORME_LATINOBAROMETRO_2008.pdf > Accesado el 20 de setiembre de 2010.

Corporación Latinobarómetro, Informe Latinobarómetro 2007, Santiago de Chile, Corporación Latinobarómetro, 2008. < http://www.der.oas.org/INFORME\%20LB\%202007.pdf > Accesado el 15 de abril de 2010.

Eguizábal, Cristina, "The United States and Central America since 2000. Free trade and Diaspora Diplomacy.” Domínguez, Jorge y Fernández, Rafael (Eds.), Contemporary US-Latin American Relations, Nueva York: Routledge, 2010, pp. 64-82.

Facultad Latinoamericana de Ciencias Sociales (FLACSO), Estudio de opinión pública en Latinoamérica 2009-2010, San José, Costa Rica, 2010: FLACSO/IPSOS/AECID. <http://www.flacso.org/ publicaciones/flacso-ipsos-final/ > Accesado el 10 de mayo de 2011.

FLACSO-Secretaría General, Dossier ALBA. Cuadernos de Integración Latinoamericana. San José, Costa Rica: FLACSO-Fundación Carolina, 2007.

Fundación para el desarrollo local y el fortalecimiento municipal e institucional de Centroamérica y El Caribe (FUNDEMUCA), “Gobierno Local y Desarrollo Territorial Endógeno.” Documento presentado en el Seminario Inaugural La década latinoamericana: Visiones de Desarrollo $e$ inserción Global. FLACSO-Secretaría General, San José, Costa Rica, 26 de abril 2011.

Ana Isabel García, "La paciencia de los pobres. Políticas sociales e integración en Centroamérica”. En: Altmann, Josette (Comp.) Cohesión social y políticas sociales en Iberoamérica. FLACSO/Fundación Carolina. Quito, Ecuador, 2009, pp, 83-104

Hernandez, Mónica, “Algunas consideraciones sobre las políticas económicas y sociales implementadas desde la década de los años 80 y la situación del empleo en Centroamérica" En: Valdés Paz, Juan y Espinoza, Mayra (Ed.) América Latina y el Caribe: La política social en el nuevo contexto. Enfoques y experiencias. Repensar América Latina Volumen 2. FLACSO/UNESCO.

Montevideo, Uruguay, 2011, pp, 163-196.

International Institute for Democracy and Electoral Assistance (IDEA), “Voter Turnout”, 2010. < http://www.idea.int/vt/ > Accesado el 10 de mayo de 2011. 
La Red Centroamericana de Centros de Pensamiento e Incidencia, Seguridad y crimen organizado transnacional. Una propuesta de acción para Centroamérica. Documento político 2. Año 2. No. 1. Guatemala, Guatemala: laRED/Fundación Konrad Adenauer, 2011.

Murillo, Álvaro, "Chinchilla no insistirá en ingreso a Petrocaribe”. La Nación, 29 de mayo, 2010. < http://www.nacion.com/2010-05-30/ElPais/NotasSecundarias/ElPais2390073.aspx > Accesado el 30 de julio de 2010.

La Nación (Editorial), “Los cuidados con Petrocaribe”. La Nación, 20 de agosto 2008. < http:// wvw.nacion.com/ln_ee/2008/agosto/20/opinion1668134.html > Accesado el 24 de abril de 2009.

La Nación, "Honduras firmará ALBA sin aprobación del Congreso". La Nación. 24 de agosto 2008. < http://wvw.nacion.com/ln_ee/2008/agosto/24/mundo1674393.html > Accesado el 24 de abril de 2009.

Laínez, Luis, “Zelaya pactó con Chávez por falta de dinero". La Prensa Gráfica, 28 de setiembre 2008. <http://www.laprensagrafica.net/lodeldia/20080928/18468.asp > Accesado el 24 de abril de 2009.

Nowalski, JorgeAsimetrías económicas, laborales y sociales en Centroamérica, San José, Costa Rica: Friedrich Ebert, 2002.

Nowalski, Jorge y Osterlof, Doris, La Integración Centroamericana: Hacia una relación virtuosa entre cohesión social y desarrollo económico. Colección Prospectiva No. 11, San José, Costa Rica: Centro Internacional para el Desarrollo Humano, 2007.

OIRLA, Desarrollo, gobernabilidad Democrática y Transparencia en el Arco del Pacífico Latinoamericano. Costa Rica: FLACSO, Secretaría General < www.flacso.org >, 2009.

Osterlof, Doris y Nowalski, Jorge, El camino hacia el desarrollo de Centroamérica: más allá de los tratados comerciales, San José, Costa Rica: RUTA, 2010, p. 82

Osterlof, Doris y Villasuso, Juan Manuel, s.f. El entorno Centroamericano ante el CAFTA-DR y la Agenda Complementaria. s. 1., s.e.

PNUD, Informe sobre Desarrollo Humano para América Central 2009-2010. Abrir espacios a la seguridad ciudadana y el desarrollo humano, Bogotá, Colombia: PNUD, 2009.

Programa Estado de la Nación, Informe Estado de la Región en Desarrollo Humano sostenible. Un informe desde Centroamérica y para Centroamérica, San José, Costa Rica: Programa Estado de la Nación, 2008.

Proyecto Estado de la Región-PNUD, Segundo Informe sobre Desarrollo Humano en Centroamérica y Panamá, San José, Costa Rica: Programa Estado de la Nación, 2003.

Proyecto Estado de la Región, Primer Informe Estado de la Región en Desarrollo Humano Sostenible, San José, Costa Rica: Proyecto Estado de la Nación, 1999.

Rojas Aravena, Francisco, “Postconflicto: Retos sociales, económicos y de seguridad”. Presentado en el Foro Internacional Esquipulas III, Guatemala, 21 de abril 2010.

Rojas Aravena, Francisco, Integración en América Latina: Acciones y Omisiones; Conflictos y Cooperación. IV Informe del Secretario General de la FLACSO, San José, Costa Rica: FLACSO-Secretaría General, 2009.

Rojas Aravena, Francisco, La Integración Regional: Un Proyecto Político Estratégico. III Informe del Secretario General de la FLACSO, San José, Costa Rica: FLACSO-Secretaría General, 2007.

Rojas Aravena, Francisco y Solís Rivera, Luis Guillermo, La integración latinoamericana. Visiones regionales y subregionales. Costa Rica: Editorial Juricentro, 2006. 
Romero, Carlos A. y Corrales, Javier, "Relations between the United States and Venezuela, 2001-2009”. Domínguez, Jorge y Fernández, Rafael (Eds.), Contemporary US-Latin American Relations, Nueva York: Routledge, 2010, pp. 218-246.

Sáenz Breckenridge, Stella (Editora), Armas Pequeñas y Livianas: una amenaza a la seguridad hemisférica, Costa Rica: Secretaría General de FLACSO, < www.flacso.org >, 2009.

Secretaría de Integración Económica Centroamericana (SIECA), Sistema de estadísticas de comercio de Centroamérica 1994-2009, Guatemala, Guatemala: SIECA, 2009. < http:// estadisticas.sieca.int/Estadisticas/Info.asp?banner=OP1 > Accesado el 10 de mayo de 2011.

SIECA, Sistemas de Estadísticas de Comercio de Centroamérica-Principales socios comerciales 2009, < www.sieca.int > Accesado el 10 de mayo de 2011.

SIECA, Estado de situación de la integración económica Centroamericana 2009, Guatemala, Guatemala: SIECA, octubre. < http://www.sieca.int/site/VisorDocs.aspx?IDDOC=Cache/ 17990000002915/17990000002915.swf > Accesado el 20 de setiembre de 2010.

Segovia, Alexander, Integración Real y Grupos de Poder Económico en América Central, San José, Costa Rica: Lara, Segura y Asociados, 2005.

Sistema de Integración Centroamericana (SICA), “Órganos e instituciones” 2010, < http:// www.sica.int/sica/instituciones.aspx?IdEnt=401 > Accesado el 20 de octubre de 2010.

Solís, Luis Guillermo, "Centroamérica y Europa: Una Asociación Compleja". Diario Extra, 1 de abril 2008. < http://www.diarioextra.com/2008/abril/01/opinion10.php > Accesado en mayo de 2008.

Solís, Luis Guillermo, "Centroamérica: los factores políticos y su inserción internacional" Nowalski, Jorge y Acuña, Jairo, ¿Quién es quién en la institucionalidad centroamericana?, San José: PNUD, 1998.

Solis, Luis Guillermo, "Pandillas y Gobernabilidad Democrática en América Latina y el Caribe" Costa, Gino y Romero, Carlos Romero (editores) ¿Qué hacer con las pandillas? Lima: Cuidad Nuestra, 2009, pp. 79-109

Solis, Luis Guillermo y Rojas Aravena, Francisco, Crimen Organizado en América Latina y el Caribe. Chile: Editorial Catalonia Ltda, 2008.

The Economist, "So near and yet so far. A special report on Latin America". The Economist. 11 de setiembre 2010. <http://www.economist.com/surveys/downloadSurveyPDF.cfm? id $=16977069 \&$ surveyCode $=\% 2577 \% 256 f \% 2>572 \% 256 c \% 2564 \&$ submit=View + PDF $>$ Accesado el 9 de mayo de 2011.

UNCTAD, “Foreign Direct Investment Flows 1970-2009". < http://unctadstat.unctad.org/ TableViewer/tableView.aspx?ReportId=88> Accesado el 10 de mayo de 2011.

UNCTAD, “External financial resources. Migrants remittances 1980-2010". < http:// unctadstat.unctad.org/TableViewer/tableView.aspx > Accesado el 10 de mayo de 2011.

\section{NOTAS}

1. Para mayor información en los temas de políticas económicas y sociales en Centroamérica, ver Mónica Hernandez, “Algunas consideraciones sobre las políticas económicas y sociales implementadas desde la década de los años 80 y la situación del empleo en Centroamérica" En: Valdés Paz, Juan y Espinoza, Mayra (Ed.) América Latina y el Caribe: La política social en el nuevo contexto. Enfoques y experiencias. Repensar América Latina Volumen 2. FLACSO/UNESCO. 
Montevideo, Uruguay, 2011. Ana Isabel García "La paciencia de los pobres. Políticas sociales e integración en Centroamérica”. En: Altmann, Josette (Comp.) Cohesión social y políticas sociales en Iberoamérica. FLACSO/Fundación Carolina. Quito, Ecuador, 2009. PNUD, Informe Regional sobre Desarrollo Humano para América Latina y el Caribe 2010 y CEPAL, La hora de la igualdad. Brechas por cerrar, caminos por abrir, 2010.

2. Al respecto ver: “Acuerdos de Esquipulas II", Guatemala, 7 de agosto de 1987, p. 3. < http:// www.acnur.org/biblioteca/pdf/2530.pdf> Accesado el 15 de abril de 2010.

3. Ibíd.

4. Sobre las implicaciones del proceso de Integración Real para la democracia y el desarrollo de la región, ver: Segovia, Alexander, Integración Real y Grupos de Poder Económico en América Central, op. cit.

5. Al respecto se puede consultar: Rojas Aravena, Francisco, La Integración Regional: Un Proyecto Político Estratégico. III Informe del Secretario General de la FLACSO, San José, Costa Rica: FLACSOSecretaría General, 2007 y Rojas Aravena, Francisco, Integración en América Latina: Acciones y Omisiones; Conflictos y Cooperación. IV Informe del Secretario General de la FLACSO, San José, Costa Rica: FLACSO-Secretaría General, 2009.

6. Al respecto ver: Solís, Luis Guillermo, "Centroamérica: los factores políticos y su inserción internacional" Nowalski, Jorge y Acuña, Jairo, ¿Quién es quién en la institucionalidad centroamericana?, San José, Costa Rica: PNUD, 1998.

7. Actualmente el SICA tiene ocho órganos, diez secretarías y veintiséis instituciones especializadas. Ver: Sistema de Integración Centroamericana, “Órganos e instituciones” < http:// www.sica.int/sica/instituciones.aspx?IdEnt=401 > Accesado el 20 de octubre de 2010.

8. Al respecto se puede consultar: Nowalski, Jorge y Osterlof, Doris, La Integración Centroamericana: Hacia una relación virtuosa entre cohesión social y desarrollo económico. Colección Prospectiva No. 11, San José, Costa Rica: Centro Internacional para el Desarrollo Humano, 2007.

9. Altmann Borbón, Josette (Editora). ALBA: ¿Una nueva forma de integración regional? Editorial TESEO, Buenos Aires, Argentina, 2011

10. Al respecto se puede consultar: Altmann, Josette, “Alba: ¿Un Proyecto Alternativo para América Latina?" ARI. 17/2008, 8 de febrero de 2008. Real Instituto Elcano. < http://www.flacso.org/ fileadmin/usuarios/documentos/Integracion/ALBA_Un_proyecto_alternativo_para_AL.pdf >;

Altmann, Josette, "El ALBA. De alternativa de integración a alianza política e ideológica". Foreign Affairs Latinoamérica, Vol. 10. No. 3, julio-setiembre de 2010, pp. 32-38; Altmann, Josette, "El ALBA, Petrocaribe y Centroamérica: ¿intereses comunes? Nueva Sociedad No. 219, enero-febrero 2009, pp. 127-144 y FLACSO-Secretaría General. Dossier ALBA, Cuadernos de Integración Latinoamericana. San José, Costa Rica: FLACSO-Fundación Carolina, 2007.

11. Altmann, Josette, "Las relaciones Unión Europea-América Latina: un balance de la situación actual". Revista Española de Desarrollo y Cooperación. Número Extraordinario. Monográfico: V Cumbre entre la Unión Europea y América Latina y el Caribe, 16 de mayo de 2008, pp. 67-84.

\section{RESÚMENES}

Este artículo parte de la base que en la integración reposa la ventaja comparativa de Centroamérica en un mundo cada vez más globalizado y competitivo. Sin embargo, hasta el momento varias paradojas han caracterizado el proceso de integración de la región: creciente 
democratización acompañada de una menor satisfacción con las democracias; profundización de las relaciones comerciales y estancamiento paralelo en sus relaciones políticas; crecimiento económico acompañado de mayor desigualdad y pobreza; y un fuerte discurso integracionista acompañado de pocas acciones concretas.

El documento también ahonda en las relaciones de Centroamérica y el mundo. En relación con Estados Unidos, la alta dependencia comercial con este país explica porque México y Centroamérica fueron los más afectados por la crisis económica. Las relaciones con la Unión Europea se fortalecieron por la firma del Acuerdo de Asociación Estratégica en 2010, siendo Centroamérica la única subregión de América Latina que ha logrado finalizar esta negociación como bloque. Por otro lado, las relaciones con Asia-Pacífico se profundizan y contribuyeron en gran medida a la pronta recuperación económica de estos países luego de la crisis. Finalmente, desde una perspectiva regional, el ALBA, principalmente a través de Petrocaribe, ha atraído a varios países del bloque centroamericano.

Por último, se exponen los principales desafíos a los que Centroamérica debe hacerle frente para consolidar su proceso de integración y sus relaciones con el resto del mundo. Primero, la superación de las asimetrías entre países y al interior de cada uno. Segundo, la ausencia de fondos de cohesión para erradicar las asimetrías. Tercero, la falta de voluntad de los gobiernos, así como la debilidad de las instituciones actuales de la integración y la falta de decisiones vinculantes. Debido a estos desafíos, la integración centroamericana continuará siendo una aspiración de mediano plazo.

Cet article repose sur l'idée selon laquelle l'avantage comparatif de l'Amérique centrale au sein d'une économie mondiale de plus en plus compétitive et globalisée réside dans l'intégration régionale. Pourtant, jusqu'ici, le processus d'intégration en Amérique centrale souffre de plusieurs paradoxes : la démocratisation s'accompagne d'une désaffection croissante des peuples pour la démocratie ; le resserrement des liens commerciaux contraste avec l'inertie des relations politiques ; la croissance économique est entachée par la hausse des inégalités et de la pauvreté ; et la récurrence des discours intégrationnistes occulte l'absence d'initiatives régionales concrètes.

Cette analyse explore en outre les relations de l'Amérique centrale avec le reste du monde. Sa forte dépendance commerciale vis-à-vis des États-Unis explique pourquoi l'Amérique centrale, comme le Mexique, a particulièrement souffert de la crise économique. Ses relations avec l'Union Européenne se sont renforcées grâce à la signature d'un Accord d'Association en 2010 qui fait de l'Amérique centrale la seule région d'Amérique Latine ayant réussi à finaliser ces négociations en tant que bloc commercial. Par ailleurs, les relations avec le bloc Asie-Pacifique se sont développées et ont largement contribué à la reprise économique des pays centraméricains depuis la crise. Enfin, sur le plan régional, l'ALBA, et notamment l'initiative Petrocaribe, a obtenu l'adhésion de plusieurs pays du bloc centraméricain.

Pour finir, l'auteur présente les principaux défis auxquels l'Amérique centrale doit faire face pour consolider le processus d'intégration et pour développer ses relations avec le reste du monde : 1) la persistance d'asymétries entre et au sein des pays de la région; 2) l'absence de fonds de cohésion qui pourrait réduire ces inégalités ; 3) le manque de volonté politique ainsi que les faiblesses des institutions régionales actuelles en Amérique centrale et l'absence de décisions contraignantes. Au vu de ces obstacles, l'intégration centraméricaine restera un projet à moyen terme.

This article rests upon the premise that Central America's comparative advantage in an ever more competitive and globalized economy resides in regional integration. However, until now, the regional integration process has suffered from several paradoxes: the process of democratization has been followed by a growing disaffection of the public toward democracy; the intensification of regional trade contrasts with the inertia of political relations; the record of 
economic growth is tarnished by a rise in inequality and poverty; the recurrence of integrationist discourses obscures the absence of concrete regional initiatives.

This analysis also explores Central America's relations with the rest of the world. Its strong dependence on US trade explains why Central America, like Mexico, was particularly affected by the economic crisis. Central America strengthened its ties with the European Union by signing an Association Agreement in 2010, making it the only region of Latin America that managed to finalize these negotiations as a trade bloc. In addition, it has developed its partnership with the Asia-Pacific bloc, which has largely contributed to the economic recovery of Central American countries since the crisis. Finally, at the regional level, ALBA, and more specifically the Petrocaribe program, has gained the support of several Central American countries.

To conclude, the author presents the main challenges that Central America will have to face to reinforce the regional integration process and strengthen its ties with the rest of the world: 1) the persistence of asymmetries between and within Central American countries; 2) the absence of regional cohesion funds that might reduce these inequalities; 3 ) the lack of political will, along with the weakness of current regional institutions and the absence of binding decisions. In the light of these obstacles, Central American integration will remain a medium term project.

\section{ÍNDICE}

Mots-clés: asymétrie, cohésion sociale, croissance économique, institutions, Intégration, volonté politique

Keywords: asymmetry, economic growth, institutions, Integration, politic will, social cohesion Palabras claves: asimetrias, cohesión social, crecimiento económico, institucionalidad, Integración, voluntad política

\section{AUTOR}

\section{JOSETTE ALTMANN BORBÓN}

Coordinadora Regional de Cooperación Internacional de la Secretaría General de la Facultad Latinoamericana de Ciencias Sociales (FLACSO), Directora del Observatorio de Integración Regional Latinoamericana (OIRLA). Profesora en las Facultades de Ciencias Sociales y Educación de la Universidad de Costa Rica. 